\title{
A Scientometric Visualization Analysis for Night-Time Light Remote Sensing Research from 1991 to 2016
}

\author{
Kai Hu ${ }^{1}$ (1), Kunlun $\mathrm{Qi}^{2}$, Qingfeng Guan ${ }^{2, *}$, Chuanqing $\mathrm{Wu}^{3,4}{ }^{3}$ Jingmin $\mathrm{Yu}^{5}$, Yaxian Qing ${ }^{1}$, \\ Jie Zheng ${ }^{1}$, Huayi $\mathrm{Wu}^{1}$ and $\mathrm{Xi} \mathrm{Li}^{1}$ \\ 1 The State Key Laboratory of Information Engineering in Surveying, Mapping and Remote Sensing, \\ Wuhan University, Wuhan 430079, China; hukai@whu.edu.cn (K.H.); qingyaxian@whu.edu.cn (Y.Q.); \\ zhengjie@whu.edu.cn (J.Z.); wuhuayi@whu.edu.cn (H.W.); li_rs@163.com (X.L.) \\ 2 Faculty of Information Engineering, China University of Geosciences (Wuhan), Wuhan 430074, China; \\ qikunlun@cug.edu.cn \\ 3 Economics and Management School, Wuhan University, Wuhan 430079, China; wuchuanqing@whu.edu.cn \\ 4 Center for Regional Economics Research, Wuhan University, Wuhan 430079, China \\ 5 Changjiang Spatial Information Technology Engineering Co., Ltd, Wuhan 430000, China; \\ yujingmin@whu.edu.cn \\ * Correspondence: guanqf@cug.edu.cn; Tel.: +86-27-67883728
}

Received: 31 May 2017; Accepted: 1 August 2017; Published: 4 August 2017

\begin{abstract}
In this paper, we conducted a scientometric analysis based on the Night-Time Light (NTL) remote sensing related literature datasets retrieved from Science Citation Index Expanded and Social Science Citation Index in Web of Science core collection database. Using the methods of bibliometric and Social Network Analysis (SNA), we drew several conclusions: (1) NTL related studies have become a research hotspot, especially after 2011 when the second generation of NTL satellites, the Suomi National Polar-orbiting Partnership (S-NPP) Satellite with the Visible Infrared Imaging Radiometer Suite (VIIRS) sensor was on board. In the same period, the open-access policy of the long historical dataset of the first generation satellite Defense Meteorological Satellite Program's Operational Linescan System (DMSP/OLS) started. (2) Most related studies are conducted by authors from USA and China, and the USA takes the lead in the field. We identified the biggest research communities constructed by co-authorships and the related important authors and topics by SNA. (3) By the visualization and analysis of the topic evolution using the co-word and co-cited reference networks, we can clearly see that: the research topics change from hardware oriented studies to more real-world applications; and from the first generation of the satellite DMSP/OLS to the second generation of satellite S-NPP. Although the Day Night Band (DNB) of the S-NPP exhibits higher spatial and radiometric resolution and better calibration conditions than the first generation DMSP/OLS, the longer historical datasets in DMSP/OLS are still important in long-term and large-scale human activity analysis. (4) In line with the intuitive knowledge, the NTL remote sensing related studies display stronger connections (such as interpretive frame, context, and academic purpose) to the social sciences than the general remote sensing discipline. The citation trajectories are visualized based on the dual-maps, thus the research preferences for combining the environmental, ecological, economic, and political science disciplines are clearly exhibited. Overall, the picture of the NTL remote sensing research is presented from the scientist-level, topic-level, and discipline-level interactions. Based on these analyses, we also discuss the possible trends in the future work, such as combining NTL studies with social science research and social media data.
\end{abstract}

Keywords: scientometric analysis; NTL; DMSP/OLS; Suomi NPP; VIIRS DNB; bibliometric; SNA 


\section{Introduction}

Night-Time Light (NTL) remote sensing, a process using satellite sensors to acquire the city lights, vessel lights, burning biomass, and gas flares, is important for studying social issues such as poverty, environment, and ecology because NTL reflects real human activities. NTL remote sensing is used as an important supplementary dataset to the census in decision making processes. Census data are not always efficient or accurate given popular mistrust of government agencies or because of data collection issues stemming from social unrest, wars, or poverty. NTL remote sensing can help mitigate the deficiencies in these datasets. Specifically, NTL can be used to investigate different types of development issues related to human activities [1], including ecological pressures, the degree of country-level economic activity, the rate of city-level urbanization, and light pollution.

NTL remote sensing research is attracting wider attention beyond remote sensing specialists and geographers. In 2011, Chen et al. used the NTL imagery data as the proxy for economic analysis [2] and found that the luminous areas in NTL imagery were highly correlated with economic activities. The journal Science in 2015 published a paper focusing on large-scale poverty using mobile phone and NTL remote sensing dataset [3]. In 2016, Science published another paper that noted the importance of NTL imagery for understanding poverty [4]. The reasons of increasing interest in NTL remote sensing data as a proxy to investigate different human activities are complex and related to several factors.

One of the principal reasons explaining the emergence of this research area is the development of satellite sensors. Most satellites capture imagery data in the daytime rather than the nighttime. Only a small number of satellites are capable of capturing nighttime imagery data and the resolution is relatively low. Such satellites first became available in the early 1970s. However, NTL remote sensing was not an active area of research until 1992, when Elvidge, C.D. created a team at National Oceanic and Atmospheric Administration (NOAA) to construct the NTL dataset [5]. Much research was conducted based on the "stable light" dataset provided by this team, including work on economics [2], ecology [6], urbanization [7], and human settlements [8]. However, this only partially explains why and how the NTL remote sensing evolved to become such a dynamic research area. A systematic analysis of the evolutionary path of this research area might reveal some answers.

In this paper, we use the bibliometric analysis and Social Network Analysis (SNA) to make a systematic review of published NTL remote sensing studies. Different from traditional interpretive reviews, the bibliometric method and SNA are data-driven analyses that expose the hidden structures of a domain by data mining the literature, examples of metrics derived from these techniques include the H-index [9], co-word network [10], co-cited references or co-cited authors [11], and the social networks of co-authors [12]. Research using these methods have been conducted in many earth science related disciplines, including discipline level analyses of Geographic Information System (GIS) development [13], transport geography [14], and topical level analysis of Digital Elevation Models (DEMs) [15] and geo-ontology [16]. The journal Remote Sensing published an article that systematically reviewed applications that utilized the Defense Meteorological Satellite Program/Operational Linescan System (DMSP/OLS) datasets [17]. The analysis in this paper however, depended on qualitative interpretation and categorization, which inevitably reflects the subjective biases of the authors. Moreover, a description and discussion of the second-generation Suomi National Polar-orbiting Partnership (S-NPP) satellite are lacking. Therefore, we have conducted scientometric visualization and data-driven analysis of this field.

Data-driven (automation with software or by hand) analysis and visualization have advantages, including greater objectivity, and providing a structural frame for cognition, thus revealing patterns that otherwise might escape attention. Data-driven analysis provides objective clues indicating key authors, references, organizations, countries, and topics. A structural frame that empirically described author or citation network channels interpretation, offering a means to synthesize and interpret discrete bit and pieces of information that have no meaning in themselves, such as citations or references. Machine learning methods, like Mutual Information, Term frequency- Inverse Document Frequency (TF-IDF), and the semantic analysis using Latent Dirichlet Allocation (LDA) or Latent Semantic 
Index (LSI) are various techniques for extracting meaningful patterns and synthesizing knowledge. These analyzing methods deal with high dimensional data supporting deeper analysis. In addition, visualization as an intuitive tool allows researchers to grasp research content directly. Applying these analyzing and visualization methods can provide a new perspective for understanding the NTL remote sensing field and help researchers in related fields understand the development of NTL remote sensing research.

Our analysis of "NTL remote sensing" consists of four parts. A basic bibliometric analysis provides an overall quantitative estimation of the field. Secondly, research communities are influential because their continuous work deepens and enriches this area of research. Analyzing the biggest author groups and their topical focuses however, might overshadow newly emerging or specialized topics addressed by independent authors or authors from smaller groups. Thus, we conduct an analysis based on the co-word or co-citation networks, representative of domain knowledge to detect emerging trends. Finally, as our initial analysis indicated that NTL has more connections to the social sciences than general remote sensing discipline, we conduct a discipline level analysis of NTL remote sensing to help researchers understand the context and its interconnections with related fields, to support future research planning.

The rest of the paper is organized as follows: Section 2 introduces how the literature datasets were collected. The methodologies and software used in the analysis are discussed in Section 3. Section 4 presents results and discussion of our analysis. Some conclusions are drawn in Section 5.

\section{Data and Materials}

In this paper, we selected the one of the most well-known and comprehensive science literature databases, the Web of Science (WOS) core collection as our data source. WOS contains the important indices including Science Citation Index Expanded (SCIE) and Social Science Citation Index (SSCI). As we aim to make a systematic analysis of "NTL remote sensing" research, we needed to find all the relevant literatures. We set the search conditions by restricting the database to the SCIE and SSCI indices and confining the time span to the years between 1991 and 2016. In line with the protocols in traditional scientometric analysis, we also set the article type to "Article" and the language type as "English". Although NTL remote sensing data have been widely adopted in many fields, the field is rooted in the category of "Remote Sensing". Therefore, we conducted a topic word search using the terms "night-time light", "nightlight", and "night light", and setting the research direction as "Remote Sensing". The full search conditions were as follows:

(TS $=\left(\right.$ night-time light ${ }^{*}$ OR night light ${ }^{*}$ OR nightlight $\left.{ }^{*}\right)$ AND SU $=($ Remote Sensing $\left.)\right)$ AND LANGUAGE: (English) AND DOCUMENT TYPES: (Article) Timespan: 1900-2016. Indexes: SCI-EXPANDED, SSCI.

Using these search conditions, 136 records were obtained. The search date was 22 December 2016. Four bibliometric techniques were applied to these data; these techniques will be fully discussed in Section 3.

\section{Methodology and Software}

Our aim is to analyze NTL remote sensing research in terms of basic metrics, core research communities, key research topics, and discipline-level interactions. To complete these tasks, the following methods were applied:

(1) Basic metrics using bibliometric analysis

The analysis of basic metrics was conducted with Histcite, a bibliometric analysis software [18]. The basic statistics include publication yearly output, yearly average number of the co-authors, core journals, and countries. These descriptive statistics provide an overall picture of the NTL research landscape. 
(2) Mining the core research community

Core research communities emerge through scientific collaboration. These communities engage in continuing efforts that develop the field, and are reflected in co-author networks. High-impact research often results from interdisciplinary collaborations among authors [19]. Moreover, young scholars are often fostered by the scientific collaboration within a research community. Therefore, studying collaborations within research communities can help reveal patterns of the evolution paths of scientific activities. Co-author network is often regarded as more efficient to study the collaborations among authors than co-citation or co-word because co-authorships reveal the strong social bonds [20] and are also regarded as more stable. Authors can cite one another and work on similar topics without direct knowledge of each other. Co-authors, however, are based on the social interactions among the researchers.

To analyze a co-author network, various approaches have been proposed. As a co-author network can be regarded as a special type of social network, Social Network Analysis (SNA) methods are applicable. For example, SNA oriented methods such as graph partitioning [21], blockmodeling [22], and modularity based optimization methods [23] have been applied to analyze the co-author network in the previous studies [12,24]. With regard to computational efficiency and ease of visualization, we utilized the modularity base method to identify the research communities. In a co-author network, a node presents an author and an edge between two nodes stands for the co-authorship between the two authors. The modularity based method use the modularity function $Q$ to describe the degree of clustering among the nodes in the network. By optimizing function $Q$, an entire network can be partitioned to several communities, i.e., the research communities in our case. The $Q$ function can be described by the Equation (1):

$$
Q=\frac{1}{2 m} \sum_{i j}\left[A_{i j}-\frac{k_{i} k_{j}}{2 m}\right] \delta\left(c_{i}, c_{j}\right)
$$

where $m$ stands for the edges that exist in the whole network, $k_{i}$ stands for the weight of all the connecting edges, and $\delta\left(c_{i}, c_{j}\right)$ is used to tag whether the $i$ th and $j$ th nodes belong to a community, in which 1 stands for true and 0 for false. By using the community detection method in our co-author network, the research communities are identified. In addition, visualization and analysis were executed with the open-source Gephi software [25].

\section{(3) Key topics and references identification}

Analyzing topics and references considering the network properties in co-word networks or co-cited reference networks provides a deeper understanding of domain knowledge. A common method for topics or references identification is counting their frequencies. Keywords with high frequency and references with many citations will be regarded as important. However, frequency alone does not reveal the intellectual structures connecting the topics or references. Therefore, a network structure made of co-word or co-cited references is needed, to better reveal the knowledge structure [20]. Much research has focused on discerning the intellectual structure of a given domain from co-word or co-citation networks $[10,11,26,27]$. Co-word or co-citation analysis borrows SNA methods, but often an analysis with SNA methods does not adequately account for temporal changes. The temporal attributes of the co-word or co-citation data must be considered, because concepts are always changing over time and the citation counts are typically aggregated by time windows.

Many methods were developed in the bibliometric and scientometric field to analyze temporal changes in topics and citations. The most commonly used methods are the PathFinder NETwork (PFNET) and the Minimum Spanning Tree (MST) [28], both of which are link-reduction algorithms. MST provides higher computation efficiency, but PFNET can better preserve the pivotal nodes in an evolution path when datasets contain a small body of literature. Therefore, the PFNET method is more suitable for mining the co-word and co-cited reference network in our case, as there were only 136 articles. In our research, seven years was set as a time unit for the 1991 to 2016 period creating 
four time intervals. Subsequently, the co-word and co-cited reference networks were processed using the PFNET method to identify clusters of topics and references. The visualization and analysis were executed with CiteSpace software [29].

(4) Discipline-level interactions

Discipline-level analysis is often lacking in both qualitative topical based interpretive reviews of the literature and scientometric analysis. When the focus is at highly abstract level, the amount of data increases enormously, making it impossible to read and interpret this material systematically or accurately. This task also challenges data-driven analysis. However, a discipline-level analysis provides a broad overview, especially when the discipline exhibits strong interdisciplinary attributes. Thus, bibliometric research has focused on establishing the degree of connectivity among a target domain and other disciplines [30]. One of the most common approaches is adopting a global science perspective [31]. By using clustering algorithm at the journal level, the journals can be clustered and visualized as a global science map [32]; the science map uses citing and cited journals clusters as the base-map data. Using this science map, we can describe and generalize discipline-level interactions, thus interpret relationships hidden behind the massive number of texts.

In this paper, we use the "Blondel Clusters" as in [32] for the base map, made of two parts: 10,330 citing journals and 10,253 cited journals. Each of the journals is mapped into the canvas as one point. By overlaying our literature dataset on the base map, citing trajectories are obtained. Thus, a discipline-level analysis is introduced, as NTL remote sensing research might be widely associated to other fields such as those in the social sciences. Therefore, discipline-level interactions can more clearly reveal this attribute, thus directing further analysis. Visualization is supported by CiteSpace [29].

\section{Results Analysis and Discussion}

\subsection{Basic Bibliometric Analysis}

\subsubsection{Yearly Publication Output}

The yearly output of a publication can indicate the research activity to some extent. In Figure 1, we can tell that the number of publications was no more than six per year until 2012. Then, this number increased to 21, three times more than most of the years prior to 2012. Therefore, we can conclude that "NTL remote sensing" is an emerging trend. 


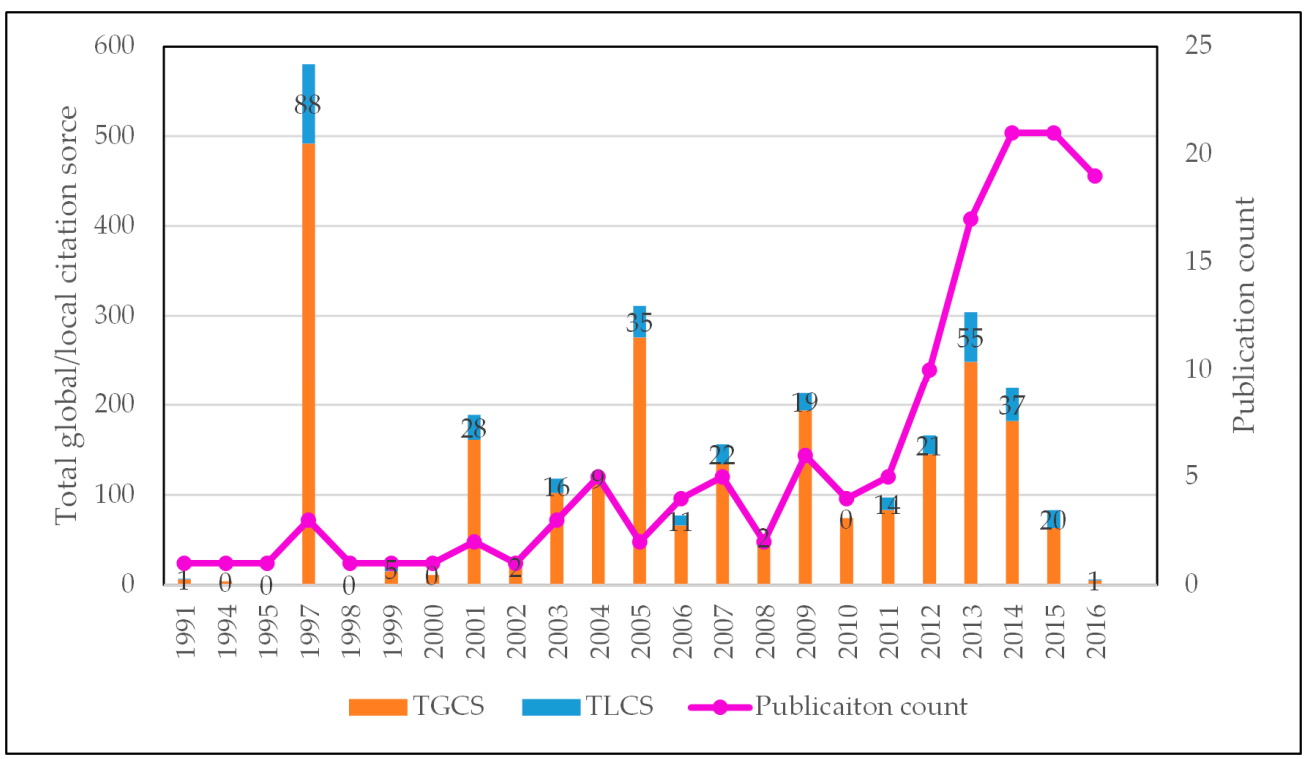

Figure 1. Yearly output of "NTL remote sensing" publication (Note: TGCS stands for total global citation score, TLCS stands for total local citation score, and the Tagged number is the TLCS value).

The number of publications indicates activity but not influence. In terms of the number of citations, which often reveals impact, many early papers in the field have higher influences. The Total Global Citation Score (TGCS) represents the number of citations recorded by WOS database and describes how the work is influencing other scientific research areas. The Total Local Citation Score (TLCS) reflects how many times the work is cited in a collection of articles. In our case, the literature collection is made of the 136 NTL remote sensing papers. In Figure 1, we can tell that three papers in 1997 have 88 local citations and 400 or so global citations. Papers in 1997 seem to build the foundation of the field. Similar patterns also appear in the papers published in 2001 and 2005.

The most recent papers can potentially start a new research direction in the field. Because of the three-year citation window, the number of citations was not stable at the time of this writing for 2014 and 2015. Papers in these years, however, already have a measurable impact to certain degree. The average number of citations for each paper is more than one, which means research during these years is both influential and active.

\subsubsection{Average Number of Co-Authors}

As shown in Figure 2, the average number of co-author has increased to a relatively high value of four. As various disciplines typically have different numbers of co-authors. In the Earth science field, the average number of co-authors was close to two or less in the early 1900s, when the scientific collaboration is not common. Nowadays, analysis requires more complicated knowledge and expertise derived from different disciplines. The trend line in the figure shows a visible increase in co-authorship, indicating that the number of coauthors on individual research papers is growing. The collaboration among authors in the field of "NTL remote sensing" is becoming more common. 


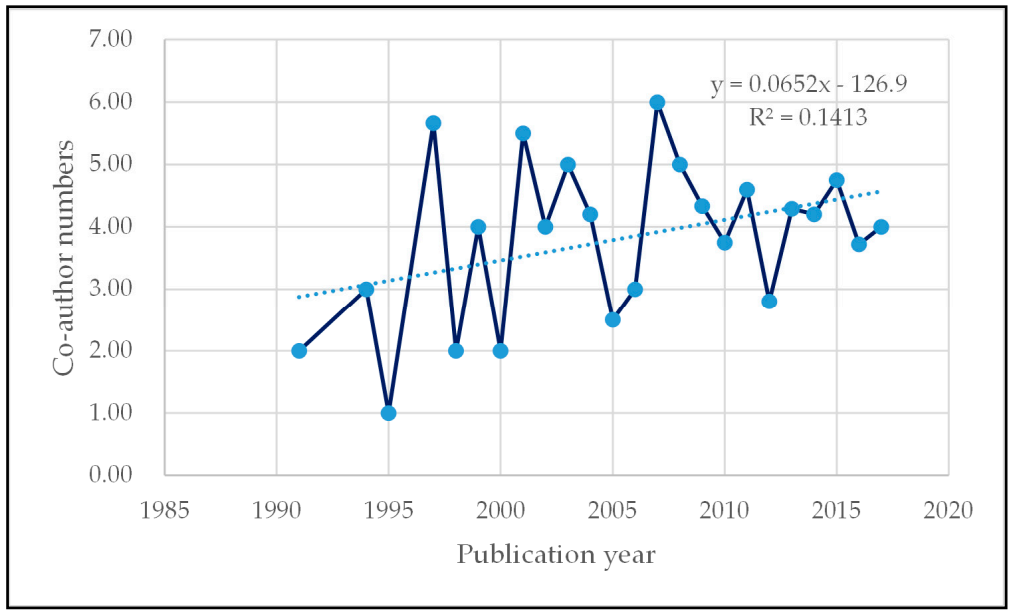

Figure 2. Average number of co-authors for each paper during the time.

\subsubsection{The Distribution of Journals}

We aggregated the number of NTL remote sensing articles by leading journals, together with the TLCS and TGCS values for those journals in Table 1. We also included in the table the rankings of the journals in the "Remote Sensing" category, provided by the Journal Citation Report (JCR).

In terms of the journal distribution, the most important journals in remote sensing have published papers on NTL research. Comparing the top 16 journals in "Remote Sensing" category, only four journals, "GPS Solution", "Journal of Geodesy", "Canadian Journal of Remote Sensing", and "Photogrammetric Record, Spatial Statistics" do not contain papers of this topic. Therefore, we can conclude that the "NTL" has drawn attention from most remote sensing journals.

Journals have varying preferences when selecting papers for publication. The amount of papers on a given topic indicates the aim and scope of a journal to some extent. From the number of papers published in the listed journals, the three journals International Journal of Remote Sensing, Remote Sensing, and Remote Sensing of Environment have published the largest number of papers on NTL topics. The three journals published more papers on this topic can be regarded as representative journals. 
Table 1. Journals publishing papers on the NTL remote sensing.

\begin{tabular}{clcccc}
\hline ID & \multicolumn{1}{c}{ Journal } & Recs & TLCS & TGCS & JCR Ranking \\
\hline 1 & International Journal of Remote Sensing & 39 & 143 & 803 & 13 \\
\hline 2 & Remote Sensing & 27 & 29 & 121 & 5 \\
\hline 3 & Remote Sensing of Environment & 20 & 86 & 517 & 1 \\
\hline 4 & Radio Science & 14 & 0 & 140 & 19 \\
\hline 5 & Remote Sensing Letters & 8 & 15 & 64 & 15 \\
\hline 6 & IEEE Transactions On Geoscience And Remote Sensing & 6 & 11 & 208 & 4 \\
\hline 7 & $\begin{array}{l}\text { IEEE Journal of Selected Topics In Applied Earth } \\
\text { Observations And Remote Sensing }\end{array}$ & 4 & 3 & 10 & 11 \\
\hline 8 & $\begin{array}{l}\text { International Journal of Applied Earth Observation And } \\
\text { Geoinformation }\end{array}$ & 4 & 12 & 77 & 3 \\
\hline 9 & Journal of Applied Remote Sensing & 3 & 0 & 1 & 24 \\
\hline 10 & GIScience and Remote Sensing & 2 & 2 & 15 & 9 \\
\hline 11 & IEEE Geoscience And Remote Sensing Letters & 2 & 6 & 12 & 10 \\
\hline 12 & ISPRS Journal of Photogrammetry And Remote Sensing & 2 & 28 & 169 & 2 \\
\hline 13 & Photogrammetric Engineering And Remote Sensing & 2 & 51 & 310 & 18 \\
\hline 14 & Earth Observation And Remote Sensing & 1 & 0 & 0 & \#N/A \\
\hline 15 & International Journal of Digital Earth & 1 & 0 & 0 & 7 \\
\hline 16 & ISPRS International Journal of Geo-Information & 1 & 0 & 0 & 26 \\
\hline
\end{tabular}

Note: Recs stands for the publication amount; TGCS stands for total global citation score; TLCS stands for total local citation score; and JCR ranking stands for the ranking list for journals of the "Remote Sensing" category from the Journal Citation Reports in 2016.

In term of impacts, some journals have published fewer papers but with relatively high citation counts. The extreme cases are the following journals, ISPRS Journal of Photogrammetry and Remote Sensing (two publications with TGCS of 169), Photogrammetric Engineering and Remote Sensing (two publications with TGCS of 310), and IEEE Transactions on Geoscience and Remote Sensing (six publications with TGCS of 210). In contrast, some journals have published relatively more paper but with less impact, such as Remote Sensing. This may also be because Remote Sensing is a relatively new journal.

\subsubsection{Main Research Countries}

We collected the top ten countries producing NTL remote sensing research, in Table 2. Each country has its own research demands. The USA and China have many produced the most articles and citations related to NTLs, more than $80 \%$ of the total publications. Therefore, we can infer that the USA and China are the leading research centers. The USA has the greatest influence, with USA based authors having 1835 global citations. This may be because much of the foundational work was conducted in the USA.

A quantitative bibliometric analysis can provide objective descriptions of the development of a field in a convincing way. Taking the yearly output as an example, researchers studying the field of NTL research intuitively argued that since the launch of the second generation NTL satellite, the research with NTL light has become more active [33]. Researchers have also argued that the research activity is related to the development of new sensor systems [33]. However, no quantitative data support these judgments. These arguments can be confirmed and verified by quantitative bibliometric analysis. By systematically analysis the content of the literature, we can see that the increase in the count of published papers is associated with changes in the DMSP/OLS public access policy. Because access to this data is becoming easier, we infer that more researchers are conducting research with these new NTL data. In addition, the launch of the new generation of NTL satellite in 2011 definitely drew the attention of more researchers to the potential uses of this rich data. 
Table 2. Top ten productive countries studying the NTL remote sensing.

\begin{tabular}{cccccc}
\hline Id & Country & Recs & TLCS & TGCS & Percentage \\
\hline 1 & USA & 76 & 306 & 1835 & $55.88 \%$ \\
2 & China & 38 & 56 & 274 & $27.94 \%$ \\
3 & Japan & 10 & 17 & 141 & $7.35 \%$ \\
4 & Israel & 8 & 12 & 96 & $5.88 \%$ \\
5 & Australia & 7 & 29 & 132 & $5.15 \%$ \\
6 & India & 7 & 9 & 92 & $5.15 \%$ \\
7 & UK & 6 & 6 & 67 & $4.41 \%$ \\
8 & Italy & 4 & 22 & 120 & $2.94 \%$ \\
9 & Brazil & 3 & 11 & 52 & $2.21 \%$ \\
10 & Germany & 3 & 7 & 46 & $2.21 \%$ \\
\hline
\end{tabular}

Note: Recs stands for the publication amount; TGCS stands for total global citation score; TLCS stands for total local citation score.

\subsection{Core Research Communities}

\subsubsection{Co-Authorship in Social Network Analysis (SNA)}

Co-authorship among the scientists reveals social bonds. Collaborations among authors from diverse backgrounds often result in high-impact research. Therefore, co-author network analysis is widely used to analyze the evolution of a domain. We conducted an analysis related to the main research members of the NTL co-author networks, their focus topics, and their roles in scientific collaboration. Before we present this analysis, we will discuss several SNA metrics. From simple to complex, we group the SNA metrics from the basic metrics to the more complex metrics that describe the function of the nodes (individual authors) in a network.

- Degree, in-degree (IDE), and out-degree (ODE): Degree can be defined as the total count of nodes connected to a target node in a network. In-degree is the number of nodes that are connected to a target node in a directed network. Out-degree is the number of nodes that are connected from a target node in a directed network. In our analysis, degree represents the number of co-authors connected to the target author; in-degree refers to the number of times a target author is a co-author but not the first author and out-degree represents the number of times when target author is a first author.

- Betweenness Centrality (BC) degree: The BC degree of a target node equals to the number of the shortest paths from all nodes to all nodes that pass through the target node. In our analysis, authors with high BC degree connect more sub-graphs of a co-author network. Removing these nodes (individual authors) from the network will result in graph partition.

- Closeness Centrality (CC) degree: CC degree is also based on the shortest paths. Different from $\mathrm{BC}$ degree, $\mathrm{CC}$ degree means the sum of the length of all shortest path from all nodes to all nodes that pass the target node. In our case, high CC degree refers to the author who is closer to various resources, thus more likely to undertake research in the future.

- Eigenvector Centrality (EC) degree: EC degree is designed to take care of the situation that traditional computation of degree does not consider who is connecting, because connection with important nodes will contribute more to the importance of the target node. EC assigns the relative degree to all nodes in the network instead of the original degree, therefore can reveal the real relative importance in term of the whole network.

- Clustering Coefficient (CCO): Clustering coefficient denotes the possibility of co-authors of an author collaborating with each other. It is also the basic characteristic of the small-world effect. Small world refers to the theory that every person is connected to every other person within six degrees of separation. A high CCO score suggests that collaboration is fixed within a small circle of researchers. 
In this paper, we selected co-author groups, i.e., identified research communities by applying a community detection method based on modularity function optimization [34]. Research communities however, do not behave the same way, thus communities generate co-author groups of varying sizes. Small research communities might indicate new emerging research centers in the field; alternatively, they might also indicate a research community without continuous work on a given topic. Therefore, we only selected the top eight largest research communities as our research subjects in relation to their research topics. These communities are listed in Table 3 and named after the core-authors that have highest $\mathrm{BC}$ degree.

As shown in Table 3, the largest research community holds more than $18 \%$ of the total authors. All the research communities have low MPL values. Community 4 and Community 6 have high MCC values, indicating a strong small-world effect. For clarity, we also highlighted the selected research communities in the whole co-author network map shown in Figure 3. In the figure, different colors indicate distinct research communities. The size of the node stands for the node centrality of the author, bigger size means greater influence. The arrows direct from the first authors and the other co-authors.

Table 3. Top eight largest research communities in the field.

\begin{tabular}{ccccc}
\hline Id & Co-Author Groups/Research Community & Proportion & MCC & MPL \\
\hline 1 & Elvidge, C.D., Miller S.D. & $18.43 \%$ & 0.37 & 3.507 \\
2 & Lee, S.H., Cao, C.Y. & $4.27 \%$ & 0.27 & 2.801 \\
3 & Ma, T., Zhou, C.H. & $2.92 \%$ & 0.567 & 2.397 \\
4 & Levin, N., Zhang, Q.L. & $2.25 \%$ & 0 & 2.133 \\
5 & Kyba, C., Kuechly, H. & $2.25 \%$ & 0.567 & 1.956 \\
6 & Centent, R. & $2.25 \%$ & 0 & 1.8 \\
7 & Zhuo, L. & $2.02 \%$ & 0 & 1.778 \\
8 & Li, X. & $2.02 \%$ & 0 & 1.778 \\
Total & Total co-author network & 1 & 0.176 & 3.329 \\
\hline
\end{tabular}

Note: MCC refers to the Mean Clustering Coefficient, the value is between 0 and 1, clustering coefficient donates the possibility of an authors' co-authors collaborate with each other themselves. MPL represents the Mean Path Length, which refers to the average value of the shortest path length of every two nodes. MPL along with the MCC can result in small-world coefficient when MCC is large and MPL is small [35].

\subsubsection{Data-Production Communities}

(1) Elvidge, C.D.-Miller, S.D. research community

The Elvidge, C.D.-Miller, S.D. research community is the biggest and includes the most influential authors in the NTL field. As shown in Figure 4, the size of the nodes represents the degree of the author. Bigger nodes show that an author has more connections than other authors represented by smaller nodes. Many of their articles broke new ground with new directions for research such as city light changes and urbanization, fleet detection, and the calibration of NTL datasets.

The number of members in this research community is relatively large, and difficult to identify. Hence, we used the SNA metrics to describe the author nodes in the co-author network. In Table 4, the top ten authors with highest $B C$ are shown with all their SNA metrics. We used the BC value as the basis for ranking the authors, as $\mathrm{BC}$ indicates the connectivity an author has within the network. Higher $\mathrm{BC}$ indicates that an author is collaborating with co-authors from diverse backgrounds. Removal of these author nodes will lead to fragmentation and splintering of the entire network. 


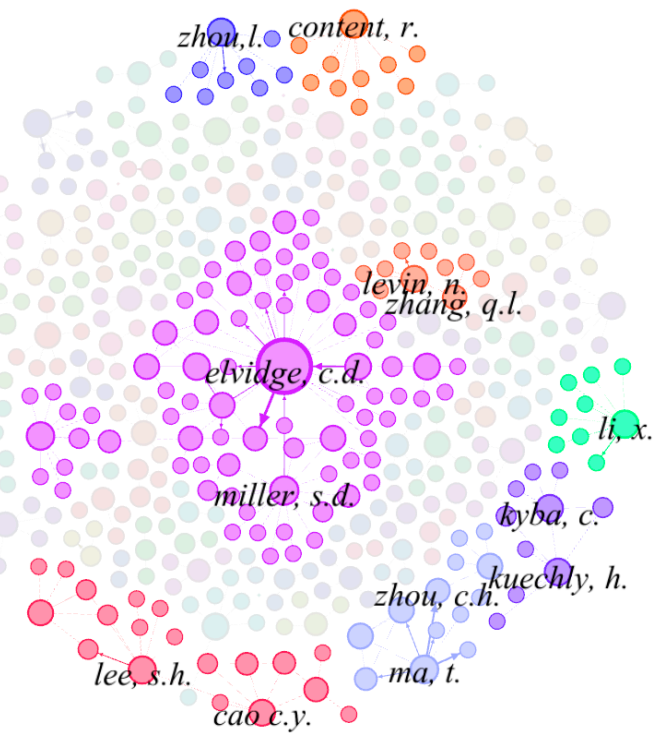

Figure 3. Top eight research communities.

Table 4. Leading authors in the research community by BC rankings.

\begin{tabular}{cccccccc}
\hline Author & IDE & ODE & Degree & CC & BC & EC & CCO \\
\hline Elvidge, C.D. & 10.00 & 23.00 & 33.00 & 0.52 & 0.86 & 1.00 & 0.02 \\
Miller, S.D. & 5.00 & 11.00 & 16.00 & 0.41 & 0.38 & 0.41 & 0.03 \\
Baugh, K. & 0.00 & 4.00 & 4.00 & 0.39 & 0.24 & 0.23 & 0.17 \\
Henderson, M. & 3.00 & 0.00 & 3.00 & 0.30 & 0.20 & 0.07 & 0.33 \\
Gong, P. & 0.00 & 9.00 & 9.00 & 0.24 & 0.17 & 0.07 & 0.03 \\
Feng, D. & 0.00 & 6.00 & 6.00 & 0.36 & 0.09 & 0.25 & 0.13 \\
Straka, W.C. & 0.00 & 5.00 & 5.00 & 0.36 & 0.07 & 0.24 & 0.10 \\
Nghiem, S.V. & 2.00 & 0.00 & 2.00 & 0.35 & 0.07 & 0.17 & 0.00 \\
Chand, T.R.K. & 2.00 & 4.00 & 6.00 & 0.36 & 0.06 & 0.24 & 0.20 \\
Imhoff, M.L. & 0.00 & 5.00 & 5.00 & 0.32 & 0.05 & 0.15 & 0.10 \\
\hline
\end{tabular}

Note: IDE stands for in-degree; ODE stands for out-degree; CC stands for Closeness Centrality; BC stands for Betweenness Centrality; EC stands for Eigenvector Centrality; CCO stands for Clustering Coefficient.

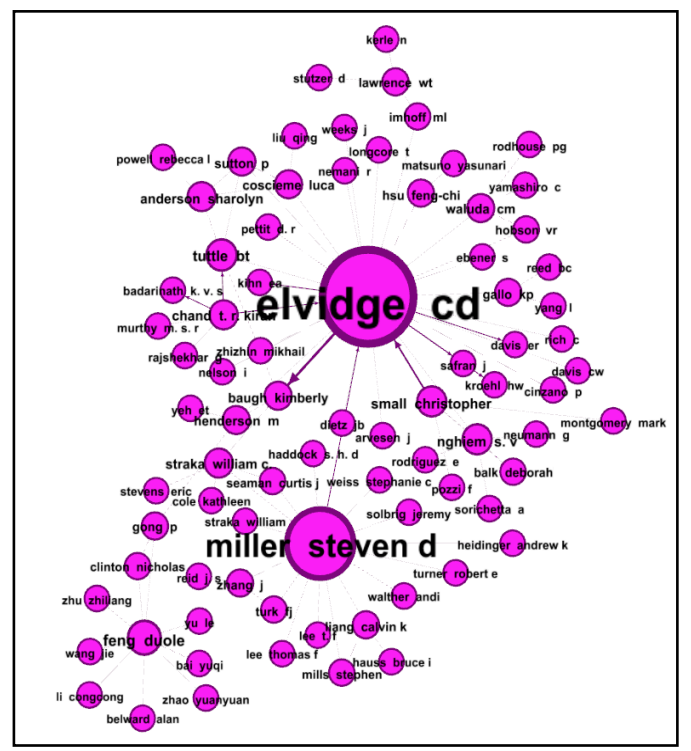

(a)

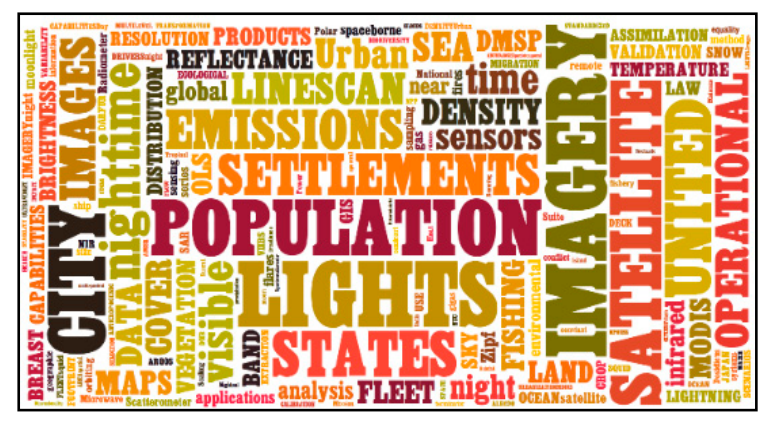

(b)

Figure 4. Elvidge, C.D.-Miller, S.D. research community: (a) co-author network; (b) related topics. 
Elvidge, C.D.'s work was fundamental and groundbreaking. In the early period, a limited body of research used NTL remote sensing data in applications. In 1997, Elvidge, C.D. pointed out the correlation between NTL and economic activity and power consumption [5]. This was pioneering work; many later studies are based on this discussion. Table 4 shows that Elvidge, C.D. is located in a central position in the co-author network, with the highest degree, IDE, ODE, CC, BC, and EC values, a reflection of his contributions. Another point of interest is his low $\mathrm{CCO}$, indicating little of the small-world effect in his co-author groups. Elvidge, C.D.'s collaborators are from very different fields and academic institutions. In our data, he is the first author of five papers and a co-author of many other papers. His five first-authored papers contribute 23 ODE connections of total 33 Degrees, meaning he is an active collaborator that introduces ideas to different research sub-communities. This behavior might be a factor that improves the diversity and creativity of his research. Moreover, in addition to research content, Elvidge, C.D. is from the National Oceanic and Atmospheric Administration (NOAA), which produces and disseminates NTL remote sensing data, an association with this institution might have influenced this choice of research topic.

Miller, S.D. is the second representative author; all his SNA metrics are also relatively high, indicating that he is a key author in the Elvidge, C.D.-Miller, S.D. research community. He works at the Cooperative Institute for Research in the Atmosphere (CIRA), an organization collaborating with the National Aeronautics and Space Administration (NASA) and NOAA. His work before 2011 was related to the first generation of NTL Satellite, the DMSP/OLS dataset. In 2006, he published a case study using the DSMP/OLS data to track bioluminescence, the so-called "milky sea" visible during the night time [36].

As a relatively young scholar, Miller, S.D.'s work focused on the second generation of NTL Satellites, the so-called Suomi NPP (S-NPP). The quality of the data from this new source exceeded the first generation DSMP/OLS data, with a spatial resolution 45-88 times higher than the first dataset. The radiometric resolution was 256 times higher than the DMSP/OLS dataset and with a finer on-orbit calibration. Along with Elvidge, C.D. in 2012, Miller, S.D. and others described this new data source in an article published in the journal of Proceedings of the National Academy of Sciences (PNAS) [37]. Miller, S.D. also conducted research with the S-NPP VIIRS dataset. In 2013, Miller, S.D. described in detail the operational and research potential of this new VIIRS dataset [38].

Miller, S.D.'s work effectively introduced the NTL dataset to researchers, previously unaware of its potential. Several researchers applied this data to fishing fleet detection. This kind of research had been done in 1970s. However, in that period, the spatial resolution of the acquired NTL datasets was too coarse. Though some authors also use the DSMP/OLS datasets to monitor fishing fleets at sea [39], the efficiency is limited. Straka et al. however, demonstrated that the DNB band in S-NPP VIIRS can help analyze the trajectories of the fleet [40].

Nghiem and Chand, also in this Elvidge, C.D.-Miller, S.D. research community, have high EC values. Subsequently, the co-authors of these two authors are important in the co-author network. Nghiem proposed a sampling method to improve the spatial resolution of the DMSP/OLS dataset, helping analyze suburban structures [41]. Although a new NTL data source was provided by S-NPP VIIRS with a spatial resolution of $750 \mathrm{~m}$, this resolution is not good enough if the analysis demands more details. In that case, Nghiem's sampling method could be also useful. Chand focused on the operational application using the DMSP/OLS dataset to analyze issues related to India, such as a regional wildfire in India [42] and the spatial characteristics of the power supply in India [43].

Key authors in the Elvidge, C.D.-Miller, S.D. community have focused on fundamental NTL dataset calibration, accuracy description, research potential, and overall review of the NTL data products produced by the first generation DMSP/OLS and the second generation S-NPP VIIRS. Authors with lower degree values have conducted more concrete analytical work solving real world problems. 
(2) Lee, S.H.-Cao, C.Y. research community

The second research community consists primarily of Chinese and Korean scholars, as shown in Figure 5. They focused on providing description and calibration for the new VIIRS NTL dataset.

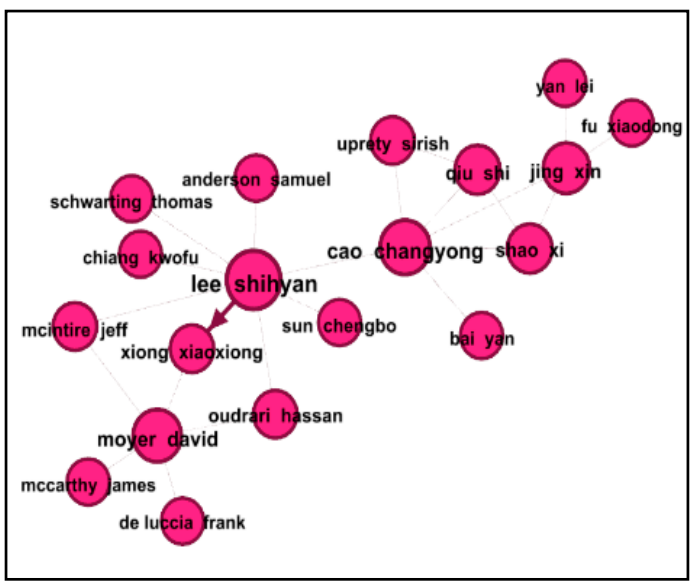

(a)

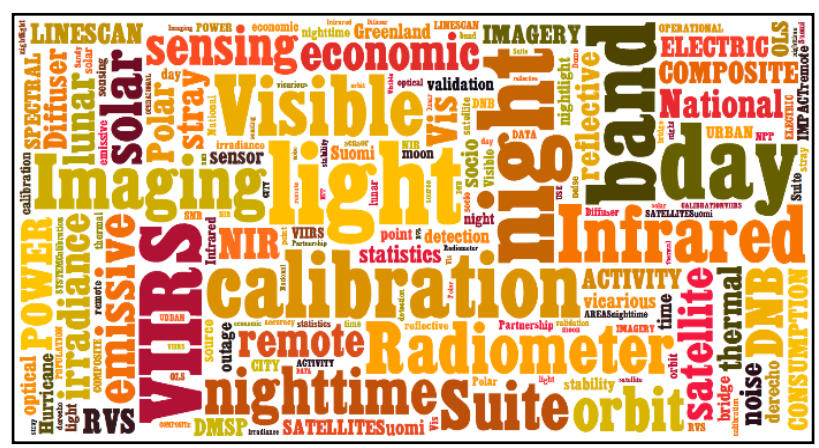

(b)

Figure 5. Lee, S.H.-Cao, C.Y. research community: (a) co-author network; (b) related topics.

Lee, S.H. is a representative author of this network as shown in Table 5. He focused on describing newly emerging sensor data records (SDR) [44], proposing new algorithms for on-orbit radiation calibration of the NTL satellite [45] and stray light description [46]. He works at the NASA Goddard Space Flight Center.

Table 5. Leading authors in the Lee SH-Cao CY research community by BC rankings.

\begin{tabular}{cccccccc}
\hline Author & IDE & ODE & Degree & CC & BC & EC & CCO \\
\hline Lee, S.H. & 0 & 8 & 8 & 0.56 & 0.73 & 1.00 & 0.00 \\
Cao, C.Y. & 3 & 3 & 6 & 0.51 & 0.58 & 0.99 & 0.20 \\
Moyer, D. & 0 & 5 & 5 & 0.35 & 0.23 & 0.48 & 0.00 \\
Jing, X. & 0 & 4 & 4 & 0.38 & 0.22 & 0.55 & 0.17 \\
Mcintire, J. & 2 & 0 & 2 & 0.42 & 0.08 & 0.43 & 0.00 \\
Oudrari, H. & 2 & 0 & 2 & 0.42 & 0.08 & 0.43 & 0.00 \\
Xiong, X.X. & 2 & 0 & 2 & 0.42 & 0.08 & 0.43 & 0.00 \\
Shao, X. & 3 & 0 & 3 & 0.38 & 0.01 & 0.60 & 0.67 \\
Qiu, S. & 0 & 3 & 3 & 0.36 & 0.00 & 0.58 & 0.67 \\
\hline
\end{tabular}

Note: IDE stands for in-degree; ODE stands for out-degree; CC stands for Closeness Centrality; BC stands for Betweenness Centrality; EC stands for Eigenvector Centrality; CCO stands for Clustering Coefficient.

Cao, C.Y. also has high SNA metric values in this co-author network. He provided quantitative descriptions for NTL calibration results, which are essential in practical usage. For example, studying nighttime aerosols requires that the NTL imagery dataset meets a set standard of calibration accuracy. Cao, C.Y. conducted accuracy validation research by estimating the accuracy of the VIIRS DNB data required for discerning power outages [47].

In the Lee, S.H.-Cao, C.Y. research community, Moyer is the first author of one paper, describing a new dataset from the Joint Polar Satellite System (JPSS). This imagery dataset was acquired by a sensor set on board the JPSS satellite in 2016. By comparing the Response Versus Scan angle (RVS) of the JPSS and S-NPP satellites, the authors claimed that JPSS satellite is consistent with its predecessor, the S-NPP satellite system [48]. Jing, X. used DMSP/OLS and S-NPP VIIRS data to study correlations between NTLs, economic metrics, and building areas. In many cases, he found that the S-NPP VIIRS data has a higher correlation with economic activity and building areas than DMSP/OLS data. Jing found 
however, that the S-NPP VIIRS data is not competitive with DMSP/OLS when using the mean NTL value or log mean NTL value to compute correlations. Jing and his co-authors also analyze possible impacting factors and concluded that the reason for S-NPP VIIRS uncompetitiveness in this regard lies in the saturation, digital processing, and acquisition times [49]. Work conducted by this group is related to the evaluation of the new data source of S-NPP. Their work provides quantitative description of the new NTL data source, therefore can better help operational applications. Although the core-authors in this network are mainly Koreans and Chinese, nevertheless they are the employees of companies or organizations that also have ties with NASA and NOAA that produce NTL data and data products.

\subsubsection{Application-Oriented Communities}

\section{(1) Ma, T.-Zhou, C.H. research community}

This community is formed by Chinese authors, as illustrated in Figure 6 and Table 6 . The work of this group focuses on the urbanization processes in China, using NTL datasets as one data source.

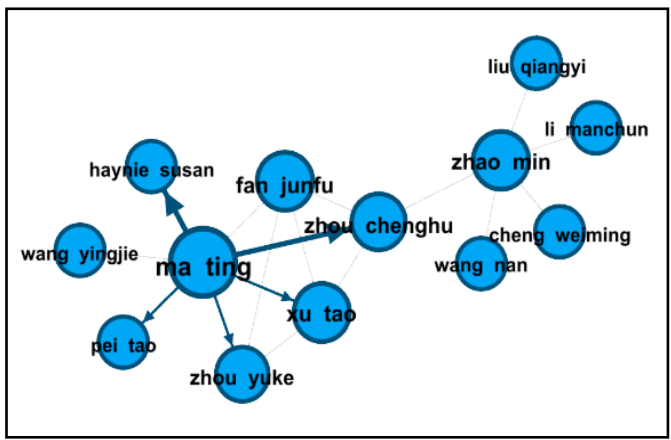

(a)

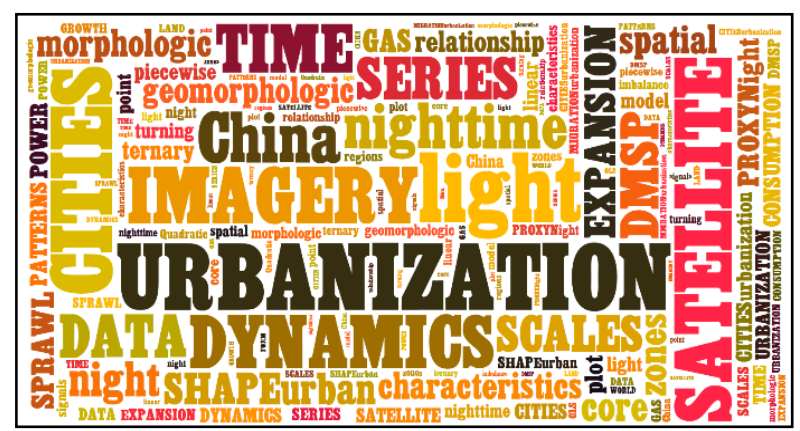

(b)

Figure 6. Ma, T.-Zhou, C.H. research community: (a) co-author network; (b) related topics.

Table 6. Leading authors in the Ma, T.-Zhou, C.H. research community ranked by BC.

\begin{tabular}{cccccccc}
\hline Author & IDE & ODE & Degree & CC & BC & EC & CCO \\
\hline Zhao, M. & 0.00 & 5.00 & 5.00 & 0.52 & 0.58 & 0.33 & 0.00 \\
Zhou, C.H. & 4.00 & 0.00 & 4.00 & 0.60 & 0.53 & 0.78 & 0.50 \\
Ma, T. & 2.00 & 7.00 & 9.00 & 0.57 & 0.48 & 1.00 & 0.24 \\
Fan, J.F. & 1.00 & 4.00 & 5.00 & 0.50 & 0.03 & 0.84 & 0.83 \\
Xu, T. & 2.00 & 3.00 & 5.00 & 0.50 & 0.03 & 0.84 & 0.83 \\
\hline
\end{tabular}

Note: IDE stands for in-degree; ODE stands for out-degree; CC stands for Closeness Centrality; BC stands for Betweenness Centrality; EC stands for Eigenvector Centrality; CCO stands for Clustering Coefficient.

Zhao, C.H. has the highest BC in this community. China is undergoing a very fast urbanization process, and traditional urbanization analytical methods are inadequate. Hence, his work targets the relationship between NTL luminosity and economic activities, to explore urbanization and relationship between the morphological characteristics of cities and human activities [50].

$\mathrm{Ma}$, T. also conducted an analysis of urbanization processes in China using the NTL remote sensing datasets for long-term DMSP/OLS data. His work offers a quantitative view of the spatial patterns of development processes occurring in different urban agglomerations [7,51]. Similarly, $\mathrm{Xu}$ defined different developmental stages of cities in China, dynamic patterns can be detected when the cities shift between development stages [52]. Fan also conducted work related to urbanization in China, studying uneven urban development and defining and applying an array of measurement methods. His work reveals that southeast of China has a more balanced development pattern than the rest of China, elsewhere there are divergent and heterogeneous patterns [53]. As this group 
focuses on macro-analysis at the city-level, the long-time series of DMSP/OLS datasets were adopted in their studies rather than the more recent VIIRS dataset. The content of these studies shows that this co-author network produces studies dealing with different problems but with similar theoretical framings to understand and explain urbanization processes in China.

(2) Levin, N.-Zhang, Q.L. research community

This community features Levin, N. and Zhang, Q.L. as core authors. Levin in particular, conducted global scale analysis using the S-NPP VIIRS dataset (Figure 7). New metrics in VIIRS were introduced and used to describe the characteristics of big cities with high population density [54]. In 2015, Zhang, Q.L. proposed a new NDUI index, which is a combination of the NDVI and NTL indexes to quickly depict city structures [55].

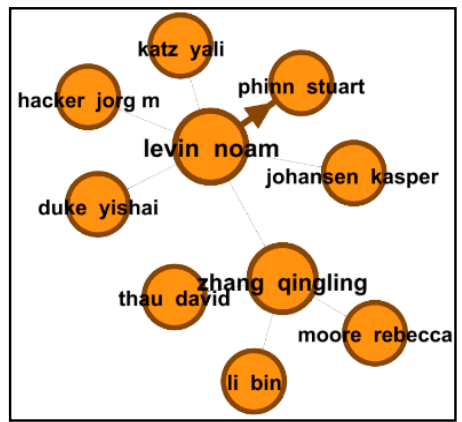

(a)

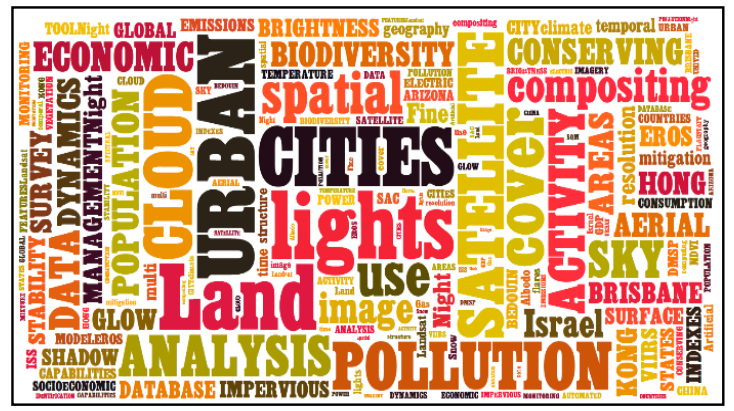

(b)

Figure 7. Levin, N.-Zhang, Q.L. research community: (a) co-author network; (b) related topics.

\section{(3) Kyba, C.-Kuechly, H. research community}

This community includes authors from Germany. Their research interests are also related to new NTL data sources, including nighttime aerial survey data and International Satellite Station (ISS), Figure 8. Kuechly adopted a new approach combining the nighttime aerial survey data and the spatial analysis methods that provides more details than either DMSP/OLS or S-NPP data alone. Traditional DMSP/OLS or S-NPP datasets are applicable to the city-level research. Although the spatial resolution of S-NPP data is improved in comparison with DMSP/OLS data, the $750 \mathrm{~m}$ spatial resolution of the S-NPP dataset is still too limited for more detailed analysis. In their work, they provided a detailed analysis of city lights in the urban areas using the aerial NTL imagery dataset, which includes light from street lamps, light reflected from building facets, and so on. Kyba, C. in 2014 [56], reviewed the then-current NTL data sources, noting the availability of new NTL data sources with higher resolution, such as the International Satellite Station (ISS). The spatial resolution of the NTL data provided by ISS can reach $10 \mathrm{~m}$, but many big cities are unavailable because of the flight angles. 


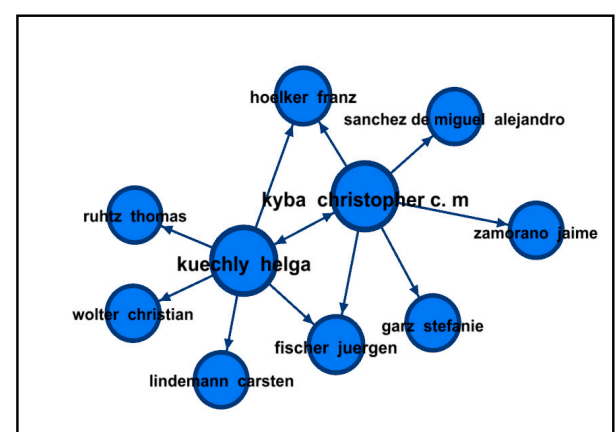

(a)

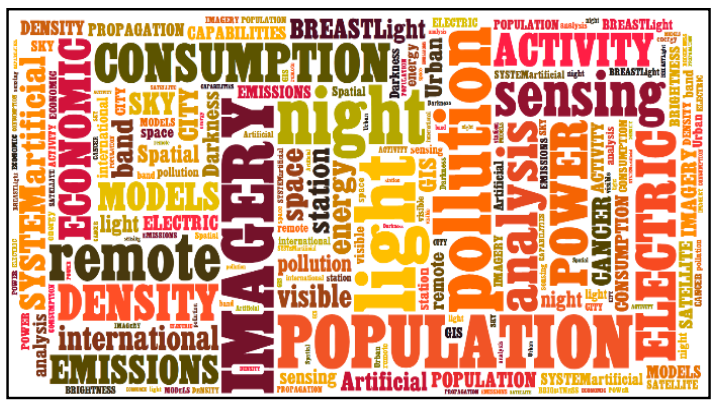

(b)

Figure 8. Kyba, C.-Kuechly, H. research community: (a) co-author network; (b) related topics.

(4) Content, R. research community

This research community is based in the UK (Figure 9), and their work focuses on NTL satellites hardware issues. Their purpose is to incorporate hyperspectral technologies into the sensor systems to collect billions of spatial elements [57].

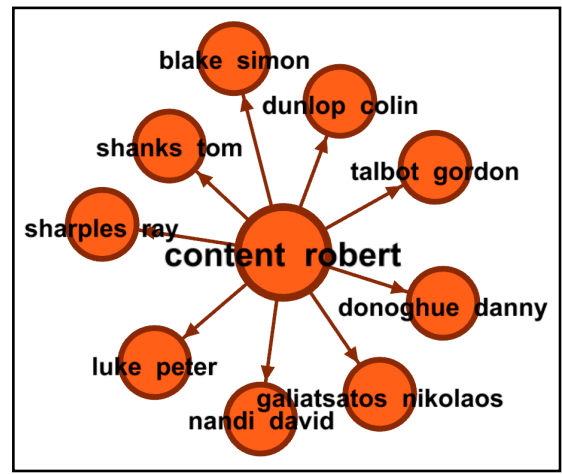

(a)

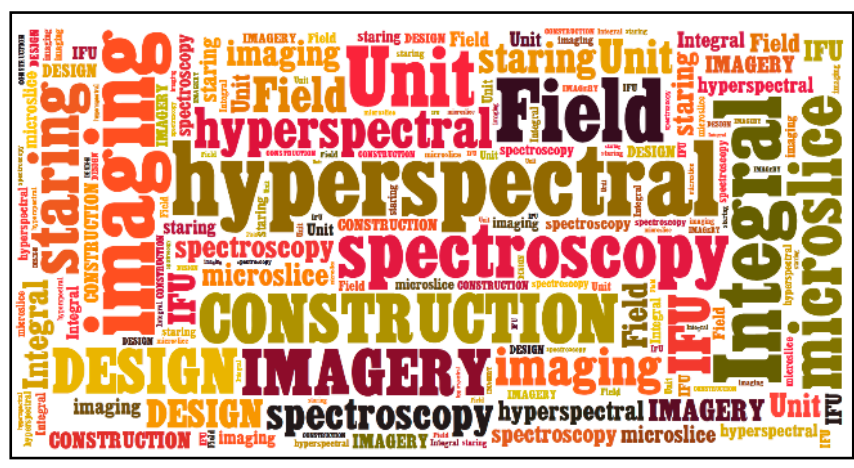

(b)

Figure 9. Content, R. research community (a) and related topics (b).

\section{(5) Zhuo, L. research community}

This research community is formed by co-authors of two papers (Figure 10). The number of co-authors in this community is fewer than that of the previous team. Zhuo, L., the leading author of this group, is from Sun Yat-sen University in China. His work in 2009 was related to Chinese urbanization [58]. Using VIIRS DNB data provided by NASA, Zhuo, L. conducted a study to solve the light saturation problem in the central regions of Chinese cities. Zhuo, L. also proposed an index to deal with the saturation problems of NTL imagery and demonstrated the efficiency of the proposed index for depicting urbanization structures [59]. This index is based on the Vegetation Adjusted NTL Urban Index (VANUI), which Zhang, Q.L. proposed in his previous work [60]. 


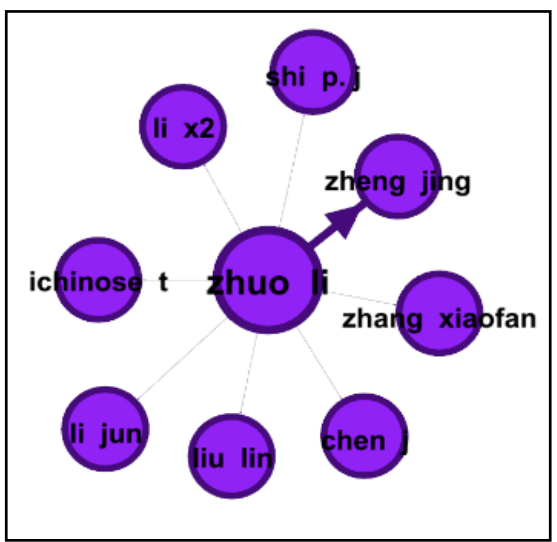

(a)

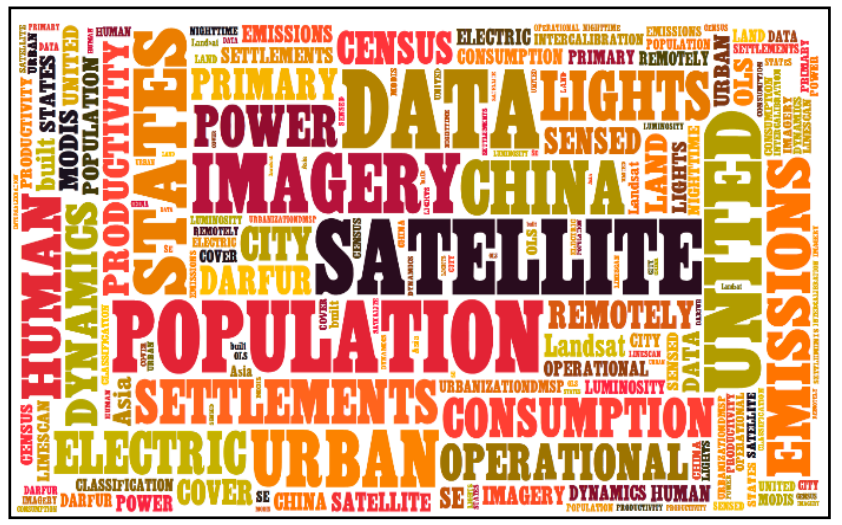

(b)

Figure 10. Zhuo, L. research community: (a) co-author network; (b) related topics.

(6) Li, X. research community

This research community is constructed by co-authors from three papers with $\mathrm{Li}$ as the first author (Figure 11). In 2012, Li focused on methods of analysis, proposing an inter-calibration model to process DMSP/OLS datasets. Calibration results generated by this method are strongly correlated to other data sources that included the NASA Moderate Resolution Imaging Spectroradiometer (MODIS), NOAA Advanced Very High Resolution Radiometer (AVHRR), and the Gross Domestic Product (GDP) data. Their work suggested that previous analyses using un-calibrated DMSP/OLS data should be re-evaluated [61].

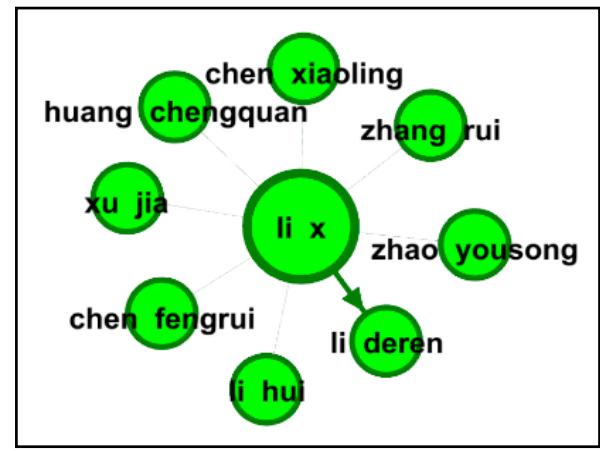

(a)

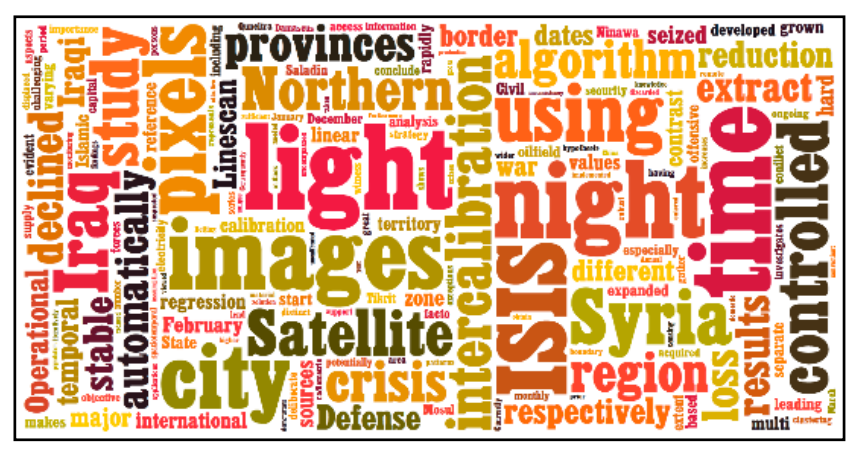

(b)

Figure 11. Li, X. research community: (a) co-author network; (b) related topics.

Later on, Li, X.'s work applied the NTL remote sensing data to evaluate the damage of the war created for Syria and Iraq. The analysis relieved the situation that subjective investigation in the district of war can be very dangerous. The NTL remote sensing revealing the human activities can help analyze the status of the human right in war torn areas $[62,63]$. Li, X. is from the Wuhan University in China, but his work offers a global view regarding deadly conflicts.

In summary, we collected the NTL applications in Table 7 exhibited by the identified communities. We can find out how the scientist-level interactions can help reveal the range of NTL dataset applications through this table. By categorizing with the different data source, we classify the applications into two types: the first generation of satellite of DMSP/OLS and the second generation of satellite of VIIRS/DNB.

Newly emerging VIIRS/DNB dataset based applications however, are relatively less frequently reported in the communities we identified. Biosphere, cryosphere, and atmosphere applications are 
relatively new and linked to a new generation of VIIIRS/DNB data. The first eight communities discussed in this section have the largest member counts, nevertheless they contain only $36.41 \%$ of the total authors in NTL domain. Work conducted by single authors or by smaller groups cannot be identified, as almost $63.59 \%$ of authors do not belong to these large co-author groups. In addition, the capability to detect newly emerging NTL application types is limited because network mining is based on the cumulative changes in the co-authors networks.

Table 7. The NTL applications and communities.

\begin{tabular}{cll}
\hline \multirow{2}{*}{ NTL Data Source } & \multicolumn{1}{c}{$\begin{array}{c}\text { NTL Applications Exhibited by Our } \\
\text { Identified Research Communities }\end{array}$} & \multicolumn{1}{c}{ Research Teams } \\
\hline \multirow{3}{*}{ DMSP/OLS } & $\begin{array}{l}\text { human activities; economic activities; power } \\
\text { supply/consumption; war in Syria }\end{array}$ & $\begin{array}{l}\text { Elvidge, C.D., Miller, S.D. (USA); Lee, } \\
\text { S.H., Cao, C.Y. (USA), Li, X. (China); }\end{array}$ \\
\cline { 2 - 3 } & $\begin{array}{l}\text { urbanization in China; geomorphic and } \\
\text { urbanization; balance problem in urbanization; } \\
\text { quantitative stages for urbanization }\end{array}$ & $\begin{array}{l}\text { Ma, T., Zhou, C.H. (China); Levin, N., } \\
\text { Zhang, Q.L. (China); Zhuo, L. (China) }\end{array}$ \\
\cline { 2 - 3 } & $\begin{array}{l}\text { bioluminescence in the sea; fleet detecting; } \\
\text { wildfire }\end{array}$ & Elvidge, C.D., Miller, S.D. (USA) \\
\hline \multirow{2}{*}{ VIIRS/DNB } & fleet detecting & \begin{tabular}{l} 
Elvidge, C.D., Miller, S.D. (USA) \\
\cline { 2 - 3 }
\end{tabular} \\
\cline { 2 - 3 } & global urbanization; urbanization in China & $\begin{array}{l}\text { Levin, N., Zhang, Q.L. (USA); Zhuo, L. } \\
\text { (China) }\end{array}$ \\
\hline
\end{tabular}

Although the co-author network cannot fully reveal the dimensions of a research field, most of the mainstream work within it can be detected. Undetected author groups are also important, but they often contain fewer authors and papers. Fewer authors may indicate less productivity on this topic and fewer papers may mean the work of these authors or groups do not have much continuity. From these analyses, we infer that the community of scientists in the NTL field is very sparsely distributed across many different organizations. The largest and second largest teams are closely related to the data-production organizations. The remaining research communities are located in China, Germany, and UK. Different research communities often have their own focused research topics. For example, Indian authors often focus on India and Chinese authors target issues relevant to China.

Through these research communities, the key authors can be efficiently identified as clues to interpret a field. The extracted information can help researchers identify canonical texts and key authors as well as emerging trends. In particular, in term of the scholars who have done some research on the related topics, these results may not be new to them. However, the information is still useful to expand their knowledge ranges or find new collaborators. In term of the scholars who are new to the NTL field, they can know who the key authors are, thus following the focal problem and what kinds of expertise knowledge will be needed as to conduct a related study. For the students who wish to start an academic career in this field, the information can help them to find suitable and qualified mentors, who have conducted the research that most attracts them.

\subsection{Important Research Topic and References}

Co-author network reveals the social connections among scientists. Some small research communities or unique authors also exhibit important research ideas, which however, are not revealed by a co-author network. Therefore, we need to use the co-word network. Co-word network reveals a larger scale of the research topics in the research community of NTL remote sensing, without considering the co-author relationships. As mentioned in the core research communities section, some authors who do not co-author on identical papers can use the same keywords. Therefore, a co-word network is a much more loosely-couple network, which can better reveal knowledge structures.

With the help of CiteSpace [29], we sliced the research time, from 1991 to 2016, into four analysis units. A co-word network was obtained using the same keywords or terms as nodes and the co-occurrence of the keywords in a paper as links. For the clarity of the co-word map visualization, we 
selected the top ten keywords of each slice to construct a network, as illustrated in Figure 12. A bigger node means that the corresponding keyword has a higher occurrence rate in the literature dataset. The purple color outside a node shows that the betweenness centrality value of the corresponding keyword is high; a purple-colored keyword node is often the turning point in the research evolutionary path and the start of the new subfield of the research. The links between the nodes are represented by different colors, which indicate different time periods.

In Figure 12, we can see that many of the topics in the early period are related to the hardware parameters (in blue color on the right side of the figure). It is not surprising that early studies focused on the hardware equipment implementation of the sensors, thus helping NTL data product acquisition. Later on, in the period from 1998 to 2004, "city lights" and "emissions" emerged as focuses. They are also purple colored nodes, meaning they were starting a new research direction of this field. Research attention shifted onto cities and human settlements. Thus, "human settlement" and "economic activities" became the focal keywords in the next period, from 2005 to 2011. During the same period, another co-word cluster, which contains topics of the quality description for NTL imagery dataset, as illustrated in the left part of the figure. Interestingly, the next generation NTL satellite, the Suomi-NPP was also launched in 2011. Figure 12 also shows that a new cluster of keywords formed during the 2011 to 2016 period, as shown in the bottom part of the figure, including the keywords "China" and "urbanization dynamics".

The overall patterns in NTL keyword evolution can be described as four stages: (1) Emerging period, when most of work is related to the hardware implementation; (2) Growing period, the focal topics are moving to what applications the NTL remote sensing data can be used for; (3) Maturing period, more attention is drawn to studying the human activities and economic activities using the NTL datasets, with another trend in this period being improving the quality of the NTL datasets; and (4) New data period, when a new data source with higher resolution is provided. Real-world application research related to the environment, ecology, economy, and health using the NTL data source has become more active areas of publication.

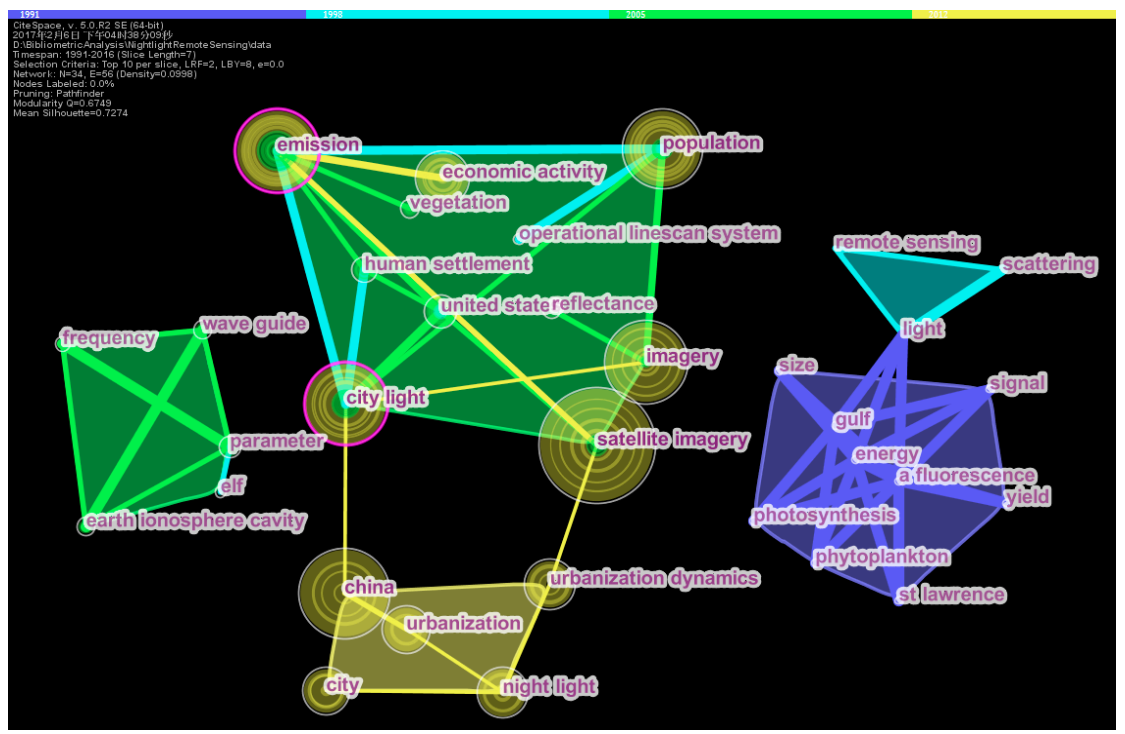

Figure 12. Visualization of a co-word network in the NTL field.

The focal topics of research are always changing. Sometimes when turning points in research emerge, it means that some technologies have become mature, a new application for the data source or a new method of analysis has appeared, or a new demand has been proposed. In the field of NTL remote sensing, all these factors are evident in the evolutionary paths of this field. For example, in the first period from 1991 to 1997, the studies focused more on the technical facets like nighttime light 
capturing capability of the NTL sensors. In the second period from 1998 to 2004, the research began to pay attention to what the acquired light dataset can be used for and the city light is identified as the focal keywords. Then in the third period from 2005 to 2011, the research trends have figured out the correlation patterns between the light emission and the economic activities. Later on, the deeper analyses based on the correlation between the light changing pattern and the urbanization process is conducted. Based on the changing patterns, we can conclude that the research foci shift from the data productions to more real-world applications. In particular, applications like socioeconomic prediction based on correlation relationships between light emissions and socioeconomic parameters indicate that this field is becoming more mature.

A co-word network is inherently incomplete, because the co-word network is generated from retrieved datasets, refined to include only one discipline, in this case "Remote Sensing". However, as an important dataset that reveals the human activities, many related studies are not refined to the only field of remote sensing. Work of Elvidge, C.D. et al. based on the NTL datasets is also listed in the journal of Social Geography [64]. The problem of incomplete datasets can be solved by considering a wider range of references mentioned in dataset, not only those in the field of remote sensing. To have a larger and detailed picture of the field that related to NTL remote sensing, we chose the co-cited reference network. Without knowing or collaboration with each other, authors can cite others' work by reading the literature. In addition, a co-cited network contains a bigger volume of datasets than a solely co-author network and is not constrained in the research directions. Therefore, more topics including out other disciplines can also be found through the identified references.

Similar to a co-word network, a bigger node in the co-cited reference network refers to a reference co-cited more frequently in the collection of articles. A purple colored node stands for an important reference that marks the beginning of a new sub research direction. These modes have high betweenness centrality values. Co-cited references reveal domain knowledge with more detailed information. By using the same link reduction methods of the co-word network, the co-cited references are clustered into five clusters, as illustrated in Figure 13.

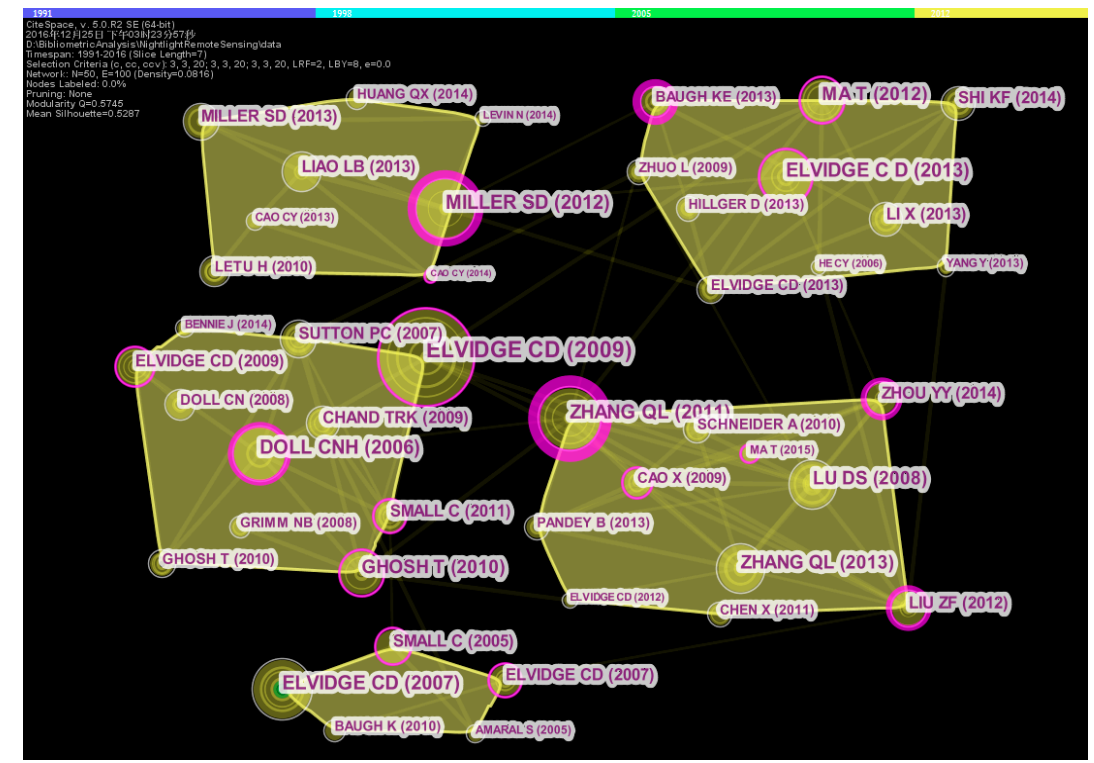

Figure 13. Co-cited reference map of the NTL remote sensing.

The color of purple means the turning points, which start new directions or connecting sub-graphs of the network. Thus, we named these clusters after the largest nodes with the purple color, namely Miller, S.D. (2012) cluster, Elvidge, C.D. (2009) cluster, Elvidge, C.D. (2007) cluster, Elvidge, C.D. (2013) cluster, and Zhang, Q.L. (2011) cluster. Note that different clusters also have connections. 
- Miller, S.D. (2012) cluster: In 2012, Miller, S.D. published a paper in the journal of PNAS. In this article, Miller, S.D. described a new NTL data source, the Suomi NPP satellite launched in 2011. This paper received high exposure with a wide audience of the journal PNAS. In addition, the new data source is a substantial improvement over the first generation of NTL data. DMSP/OLS is visible, the spatial accuracy, radiometric accuracy, and sensitivity have been enhanced by $45-88$ times higher, 256 times finer, and about 10 times higher, respectively. The calibration is also improved from un-calibration to calibration on-board [38]. This cluster represents the latest research directions using the second generation of Suomi NPP VIIRS DNB dataset.

- Elvidge, C.D. (2009) cluster: In 2009, Elvidge, C.D. published two articles using NTL data, arguing that natural gas consumption reflects the economic development level of countries. One concerned mapping the global distributed natural gas consumption using the gas flare data extracted from NTL imagery [65]. The second proposed a new poverty index for describing the spatial-explicit development analysis, based on NTL data [66]. These both deployed the DMSP/OLS data to make a connection between nighttime lights and economic activities. The poverty index generated by NTL remote sensing has an advantage over GDP as captures spatial unevenness. Similar work was also conducted in the nodes like Doll's work [67], who also produced a global economic activity map.

- Elvidge, C.D. (2007) cluster: The reference published in 2007 by Elvidge, C.D. is using the multiple source datasets to build up a global Impervious Surfaces Area (ISA) model, thus producing the global ISA distribution map [68]. Multiple source data include the coarse resolution imagery and the census data. ISA is the most common artifacts constructed by human and can be detected by the NTL remote sensing, such as roads, parking lots, etc. ISA data are ideally suited for analyzing the evolution paths of the country-level development, later studies on urbanization using ISA data are an extension on this work.

- Elvidge, C.D. (2013) cluster: In 2013, Elvidge, C.D. published two papers, one is to introduce the superior property of the NPP VIIRS data over the traditional DSMP/OLS data [69]. The other one is to build a night-fire map using the NPP VIIRS DNB dataset [70] and the quality of map can accurate to the level of sub-pixel. Similar work using the VIIRS DNB also emerge in Baugh's work [71]. Li's work is to use the NPP-VIIRS data to model the regional economic study of China [72]. Differently, Ma's work still uses the DMSP/OLS data because of the long-term analysis demands, his work is also included in the cluster [7]. Therefore, most work of this cluster can be regarded as the VIIRS application related studies.

- Zhang, Q.L. (2011) cluster: In 2011, Zhang, Q.L. studied the global and regional urbanization using the multiple terms of DMSP/OLS dataset [73]. He also introduced an effective index for in the 2013 to depict the internal development level in the core cities, namely vegetation adjusted NTL urban index (VANUI) in reference [59]. Ma's work of 2015 emerges in the cluster which studied the dynamic urbanization processes using the DMSP/OLS dataset [51]. Work of Elvidge, C.D. in 2012 also had a similar research topic and introduced a new index of Night Light Development Index (NLDI), which can be used to help depict the developing status of the cities or countries [64]. Zhou, Y. also proposed a clustering method for depicting the urban areas of a city [74]. We can conclude that this cluster is related to the topic of urbanization and city development issues.

\subsection{Discipline-Level Interactions}

Co-author and co-citation networks provide a roadmap to understand the intellectual structures of NTL research; but how the discipline can be affected by different academic purpose or application scenarios is still not clear. NTL remote sensing data are a proxy measure of human activities. Solutions to complex issues such as pollution or climate change will require expertise and knowledge from across the disciplines as well as data derived from remote sensing. Analysis of co-word and co-citation network can help NTL researchers understand the interdisciplinary value of their work. As shown by 
the NTL remote sensing related applications, topics and keywords extracted from the co-word and co-cited references in Table 8, we can obtain the overall thematic interests of the NTL scholars.

In Table 8, we see that co-word and co-cited reference networks provide richer information than co-author networks. Comparing with the review from other review paper [17,38], most types in DMSP/OLS applications have been covered and fewer types in VIIRS/DNB applications are covered. Although the manual reviewing process lacks the structuralized knowledge information and the overall importance computation in the network, they offer more concrete potential or detailed applications in new areas. This is also the limitation of SNA and Bibliometric analysis methods, which are based on the computation with the historical citation and publication datasets. Therefore, detail investigation over the possible trends still need the authors to close read and interpret the literature manually. Note that we also collected the science backgrounds, the WOS classification for discipline, behind the applications/keywords/topics. From the WOS classification column, we can tell the trends of combining various backgrounds, including many fields from the natural sciences and social sciences. However, the concrete preference and interpretation are not clear.

To analyze this interdisciplinary value of NTL studies, we compare the "NTL remote sensing" and the "Remote Sensing" by collecting results from the databases of SCIE and SSCI indices. As shown in Table 9, SCIE and SSCI stand for different scientific directions grouped into two general categories, natural sciences and social sciences. Different amounts and proportions of topics found in separate indices reflect the attributes of topics. 
Table 8. The application/topic/keyword distributions and science background of DMSP/OLS (I) and VIIRS/DNB (II).

\begin{tabular}{|c|c|c|c|}
\hline & Application/Topic/Keyword & Collected by the Other Review $[17,38]$ & $\begin{array}{l}\text { Discipline Background } \\
\text { (WoS Classifications) }\end{array}$ \\
\hline \multirow[t]{4}{*}{ I } & $\begin{array}{l}\text { human activities, power supply/consumption, war } \\
\text { in Syria }\end{array}$ & $\begin{array}{l}\text { Settlement dynamics and impacts on the environment: Urban land } \\
\text { dynamics; } \\
\text { Impacts of urbanization on soil, net primary productivity, urban } \\
\text { surface temperature and surface air temperature }\end{array}$ & $\begin{array}{l}\text { Political science, Environmental science, } \\
\text { Geosciences, Multidisciplinary }\end{array}$ \\
\hline & $\begin{array}{l}\text { economic activities, long-term urbanization in } \\
\text { China, geomorphic and urbanization, quantitative } \\
\text { stages for urbanization, gas flares, poverty index, } \\
\text { ISA distributions, VANUI, NLDI }\end{array}$ & $\begin{array}{l}\text { Demographic and socioeconomic information: population, urban } \\
\text { population, population density, "ambient population"; } \\
\text { Socioeconomic parameters: GDP, freight traffic, copper stock, poverty } \\
\text { index, per capital income; } \\
\text { Energy and electric power consumption }\end{array}$ & $\begin{array}{l}\text { Geology, Demography, Economic } \\
\text { statistics, Geography }\end{array}$ \\
\hline & bioluminescence in the sea, fleet detecting, wildfire & $\begin{array}{l}\text { Short-term light monitoring: aerosol properties and forest fire, gas flare, } \\
\text { burning area and light flash; } \\
\text { Fishing vessel monitoring }\end{array}$ & Chemistry, Analytical \\
\hline & $\begin{array}{l}\text { natural gas consumptions, balance problem in } \\
\text { urbanization }\end{array}$ & $\begin{array}{l}\text { Other applications: Anthropogenic gas emission (CO2); Nighttime } \\
\text { sky brightness and light pollution; } \\
\text { Other topics: human health, water footprint and virtual water, wars and } \\
\text { conflicts, scaling law of city size, biolumine phenomena, coral reef stress, } \\
\text { bird foraging, earthquake damage, ecosystem services, and climate station } \\
\text { classification }\end{array}$ & $\begin{array}{l}\text { Public, Environmental and Occupational } \\
\text { Health, Tropical Medicine }\end{array}$ \\
\hline \multirow{6}{*}{ II } & Global urbanization & The Cryosphere: Mid-Latitude Snow Fields; Sea Ice Edge and Extent & Ecology, Geology \\
\hline & fleet detecting & $\begin{array}{l}\text { The Hydrosphere: Sea Surface Roughness Properties via Moon Glint; } \\
\text { Coastal Waters Turbidity }\end{array}$ & Water Resources, Transportation \\
\hline & $\begin{array}{l}\text { global urbanization, urbanization in China, } \\
\text { regional economics, night-fire maps }\end{array}$ & $\begin{array}{l}\text { The Lithosphere: Soil Moisture; Volcanoes_-Ash Plumes and Pyroclastic } \\
\text { Flows; Wind-Lofted Dust }\end{array}$ & $\begin{array}{l}\text { Electrical and Electronic, Environmental } \\
\text { science }\end{array}$ \\
\hline & & The Atmosphere: Cloud Optical Properties; Lightning; Tropical Cyclones & Atmospheric Sciences, Optics \\
\hline & & $\begin{array}{l}\text { The Biosphere: City Lights and Power Outages; Ship Lights; Biomass } \\
\text { Burning }\end{array}$ & Environmental Studies \\
\hline & & Atmospheric Light Sources: Aurora; Nightglow & Atmospheric Sciences \\
\hline
\end{tabular}

Note: the topics and keywords in the Second column with bold type are the extensive keywords obtained from the co-word and co-citied reference; the words in the Third column in italic font are the reviewed content from other review paper. 
Table 9. Amount and proportion of publications in SCIE and SSCI of Remote Sensing and NTL Remote Sensing.

\begin{tabular}{cccc}
\hline Topic Search & SCIE & SSCI & SSCI/SCIE \\
\hline Remote sensing & 53,495 & 2706 & 0.05 \\
NTL remote sensing & 136 & 15 & 0.11 \\
\hline
\end{tabular}

In Table 9, we can tell that NTL remote sensing is more explicitly related to human activities than the parent domain, "Remote Sensing". This is in line with our intuitive understanding. However, the internal structure of how societal disciplines are involved with NTL remote sensing studies is not clear. An understanding of the internal structure can guide researchers plan future research in relation to the expanded audience for their work outside of their core domain, therefore, we introduce the dual-map analysis [32].

A dual-map analysis can depict journal-level distribution with disciplinary mapping across the entire range of scientific publications. There are two parts in the dual-map: collections of the citing journals and cited journal collections. Citing journals are not the same as the cited journals, the base map of the collection of citing journals on the left side of Figure 14 contains 10,330 journals while base map of the cited journal collection on the right side contains 10,253 journals. The journals on both sides of the map are clustered and visualized using graph theory based clustering methods [75]; termed "Blondel clusters" in Reference [32]. Based on the global base map of science, we can clearly distinguish citing behaviors from the citing trajectories visible on the map seen in Figure 14.

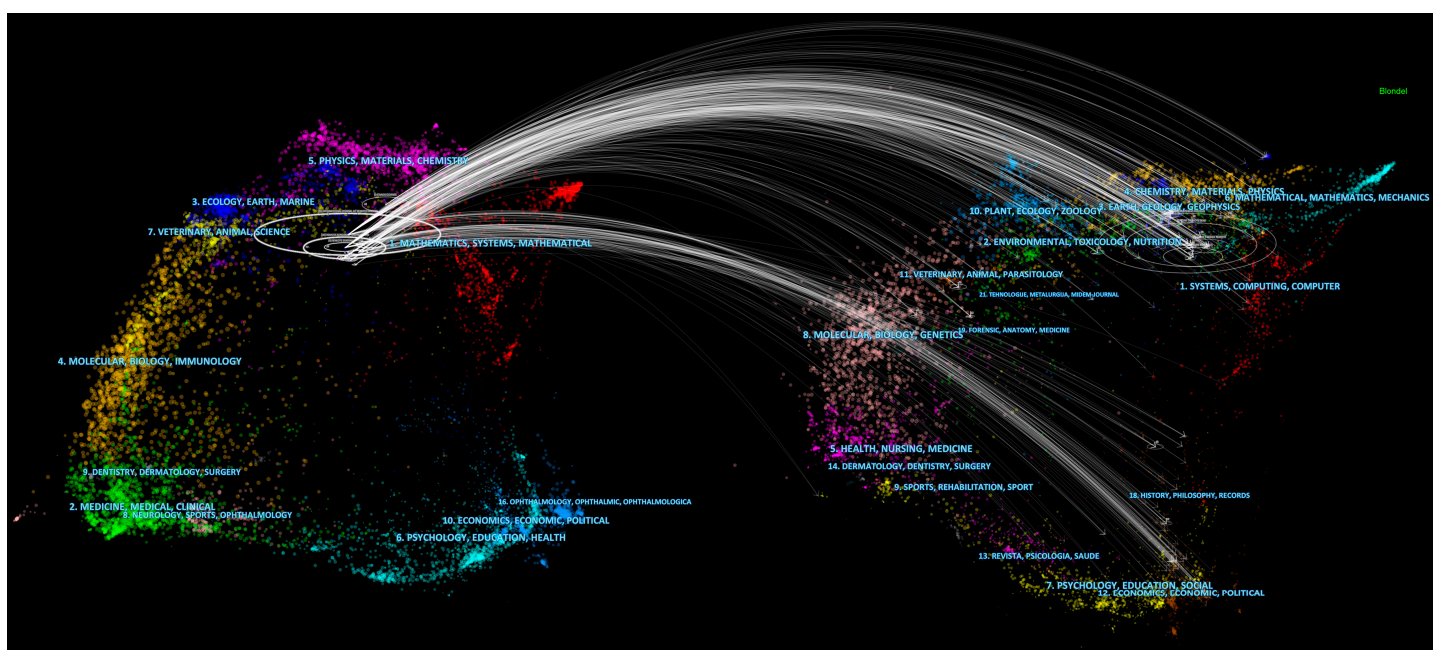

Figure 14. NTL remote sensing distribution in a global science dual-map.

On the left side of Figure 14, the citing journals are the journals that have published 136 papers in our dataset. The largest ellipse on the left denotes the journal of International Journal of Remote Sensing. On the right side, the cited journal base map is made of the journals that have published papers that cited by the 136 papers in our dataset. We can tell that a clustering phenomenon emerges in a small district of the left base map, because the 136 papers are restrained in the search conditions by "Remote Sensing" as the research direction. In contrast, on the right side, the cited papers are distributed across a relatively wider range. In addition to the "Remote Sensing" discipline, the cited papers appear clearly connected to the environment and ecology disciplines and economics and political science disciplines. In addition, papers from history and philosophy journals are cited in NTL remote sensing articles.

This knowledge of the audience for NTL research suggests that NTL data are of interest to specialists not only in remote sensing techniques, but intersects with interests, and methodological 
concerns within the social sciences. Armed with this information, NTL researchers might need to rethink the kinds of activities that could be depicted by the NTL data sources and the linkages between social phenomena and NTL data. Given the explosion of scientific data, publications and research areas, many social scientists might not even be aware that NTL data sources exist that can capture evidence of human activity patterns; the introduction of this research area to a social science audience could generate new theoretical directions and research programs. At the same time, the wider remote sensing communities, might rethink how remote sensing might be relevant to social analysis, and adapt their writing styles, accordingly. For example, NTL remote sensing can be used as supervised information inputs in deep neural networks to extract land use and land use change, issues of interest to planners and urban sociologists. Social analysis, on the other hand, could become more important in both NTL and wider remote sensing communities.

Remote sensing has always exhibited interdisciplinary attributes. We can see that in past research, many methods from machine learning and computer vision were introduced in the field of remote sensing. Computer science with more mature methods, brings in new theory and insights to solve old problems in new ways or to tackle problems thought to be unsolvable in remote sensing dataset analysis. Interdisciplinary attributes add significance operationally and theoretically. NTL remote sensing, touches upon social science related topics that are becoming focal topics such as pollution, climate change, and urbanization. NTL researchers could expand their interdisciplinary collaborations and language for depicting human activities based on empirical analysis, incorporating theoretical frameworks and questions borrowed from the social sciences, enriching both fields. Computer science is different from remote sensing, but based on similar techniques such as the data storage formats and similar processing workflows, thus it may be easier general remote sensing researchers to borrow theory and methods from computer science. Research on social and political issues is increasingly deploying mixed methods approaches to find solutions to problems, although clashing ontological and epistemological standpoints create frictions and tensions. Therefore, these differences are challenge and potential obstacle for cooperation. However, admittedly, there is also great potential for new research directions when combining very different fields.

Considering research using NTL to detect the impact of the war in Syria, disciplinary knowledge of regional politics, economics, and religion are required. The NTL dataset can provide the basic empirical measurement of changes in the nightlight emissions, but cannot provide explanation, context or an interpretive framework for understanding the significance. Social science can help provide the qualitative frame that explains what is going on these geographic districts. For example, if an author cannot understand Islamic State of Iraq and al Shams (ISIS) organizations, they cannot arrive at meaningful interpretation. Changes in the luminosities in NTL dataset can be measured quantitatively, the analysis however, cannot provide in-depth reasons explaining why the changes happens without the interpretive framework or society context provided by social science. Similarly, NTL remote sensing dataset is also used to detect fishing fleets at the sea. In areas of the Yellow Sea, fleets use artificial lights to hunt for squid or octopus detectable in NTL data sources. Commercial fishing operations must comply with natural resource management practices that apply to fishing reserves of China, South Korea, and Japan, but NTL researchers often lack knowledge of these regulations. More importantly, NTL remote sensing research currently has a very limited audience in related fields in the social, economic, and ecological sciences. This could change if an understanding of the commonalities with experts from these fields became more widely known potentially providing fruitful research partnerships. Future NTL research may benefit from more interdisciplinary collaborations from different fields rather than engineering technology.

\section{Conclusions}

In this paper, we present a systematic analysis using the clues provided by sophisticated bibliometric and SNA analysis. Several interesting conclusions drawn based on the previous analyses are summarized. NTL remote sensing is becoming a research hotspot in recent years. Most of the 
important remote sensing journals have published related papers on this topic. The most active research countries include USA and China. The largest eight research communities are identified and can be categorized as two classes: the data-production organizations and the wide spreading and scattered application-oriented research communities in different countries. By interpreting the network generated by co-word and co-cited references, we can obtain the topic evolution and the intellectual structure in the field from hardware-oriented studies to application-oriented studies. In terms of the intellectual structure, five clusters are identified: the S-NPP VIIRS DNB application, DMSP/OLS long term analysis, NTL based economic and city study, urbanization dynamic analysis using NTL light, and mapping with VIIRS DNB. NTL remote sensing stems from the field of engineering technique of remote sensing, but has more connections with human activities related to social science. The potentials of NTL research to have more connections and collaborations with the social science are identified.

These findings can benefit the scientists related to the field of NTL remote sensing in different ways. Firstly, in term of the basic quantitative metrics, scientists will have a more convincing fact basis to describe the development trend of these fields. From the social networks of the co-authors, some of the information may be not new to them, but the scientists can also benefit from the social network analysis by identifying the most suitable collaborators to conduct a future research plan. In addition, the co-word or co-cited references provide an intuitive knowledge maps for scientists to understand the research trends. Though our approach also creates some information loss because of the link reduction methods, the objectiveness of the conclusions can be assured. To a higher abstract level, the discipline interactions in highly divergent scientific research communities can help scientists further understand the potential collaboration possibilities. Our approach can also help to find new issues and board patterns related to human activities such as the anthropogenic environmental change. The urbanization is an evident example of the anthropogenic environmental change. Our finding based on the literature mining shows a clear shift from the original city light data production to the urbanization dynamics. The urbanization continuously changes the morphology of the demographic, influencing the ecology and climate. These transformations can help researchers find potentially important research topics in the later future.

The NTL remote sensing is also a data-hungry discipline, and the improvement of the spatial, radiometric, and calibration highly strengthen the capability of the data used in the related studies. For example, China has planned to launch a NTL satellite in 2017, which is also promising to increase the research interests of different fields. As reported in Miller, S.D.'s work in 2013 [38], future work may increase the resolution again, or combining with multi-spectral and multi-sourced remote sensing imagery data. Social sensing, such as using social media and user generated content as mining source [76], can also be combined or inter-calibrated. The NTL imagery dataset with high resolution can also be the input of many machine learning tasks of the real-world urban planning. It is worth noting that authors may combine the special local knowledge of their expertise to help tell a good story, as discussed in the analyses above that many authors have published papers on the topics related to the issues happened in their countries, because they are more familiar with the internal and deeper reasons for the changes in the NTL dataset. More advertising for the capability of the NTL of depicting human activities can also contribute to the thriving of NTL related research communities.

Acknowledgments: This work was supported by the National Natural Science Foundation of China (Grant Nos. 41371370 and 41671408) and the Fundamental Research Funds for the Central Universities (Grant No. 2042016kf0162).

Author Contributions: K.H. and Q.G. conceived and designed the experiments; K.H. and K.Q. performed the experiments and analyzed the data; Y.Q. and J.Z. contributed analysis tools; H.W., Q.G., C.W., X.L. and J.Y. contribute to the analysis and discussion of the results; and K.H. wrote the paper and all authors read the paper and provided revision suggestions.

Conflicts of Interest: The authors declare no conflict of interest. 


\section{References}

1. Elvidge, C.D.; Safran, J.; Tuttle, B.; Sutton, P.; Cinzano, P.; Pettit, D.; Arvesen, J.; Small, C. Potential for global mapping of development via a nightsat mission. GeoJournal 2007, 69, 45-53. [CrossRef]

2. Chen, X.; Nordhaus, W.D. Using luminosity data as a proxy for economic statistics. Proc. Natl. Acad. Sci. USA 2011, 108, 8589-8594. [CrossRef] [PubMed]

3. Blumenstock, J.; Cadamuro, G.; On, R. Predicting poverty and wealth from mobile phone metadata. Science 2015, 350, 1073-1076. [CrossRef] [PubMed]

4. Blumenstock, J.E. Fighting poverty with data. Science 2016, 353, 753-754. [CrossRef] [PubMed]

5. Elvidge, C.D.; Baugh, K.E.; Kihn, E.A.; Kroehl, H.W.; Davis, E.R.; Davis, C.W. Relation between satellite observed visible-near infrared emissions, population, economic activity and electric power consumption. Int. J. Remote Sens. 1997, 18, 1373-1379. [CrossRef]

6. Imhoff, M.L.; Lawrence, W.T.; Elvidge, C.D.; Paul, T.; Levine, E.; Privalsky, M.V.; Brown, V. Using nighttime DMSP/OLS images of city lights to estimate the impact of urban land use on soil resources in the united states. Remote Sens. Environ. 1997, 59, 105-117. [CrossRef]

7. Ma, T.; Zhou, C.; Pei, T.; Haynie, S.; Fan, J. Quantitative estimation of urbanization dynamics using time series of DMSP/OLS nighttime light data: A comparative case study from China's cities. Remote Sens. Environ. 2012, 124, 99-107. [CrossRef]

8. Small, C.; Pozzi, F.; Elvidge, C.D. Spatial analysis of global urban extent from DMSP-OLS night lights. Remote Sens. Environ. 2005, 96, 277-291. [CrossRef]

9. Hirsch, J.E. An index to quantify an individual's scientific research output. Proc. Natl. Acad. Sci. USA 2005, 102, 16569-16572. [CrossRef] [PubMed]

10. Callon, M.; Courtial, J.-P.; Turner, W.A.; Bauin, S. From translations to problematic networks: An introduction to co-word analysis. Soc. Sci. Inf. 1983, 22, 191-235. [CrossRef]

11. Small, H. Co-citation in the scientific literature: A new measure of the relationship between two documents. J. Am. Soc. Inf. Sci. 1973, 24, 265-269. [CrossRef]

12. Mali, F.; Kronegger, L.; Doreian, P.; Ferligoj, A. Dynamic scientific co-authorship networks. In Models of Science Dynamics; Springer: Berlin/Heidelberg, 2012; pp. 195-232.

13. Tian, Y.; Wen, C.; Hong, S. Global scientific production on GIS research by bibliometric analysis from 1997 to 2006. J. Informetr. 2008, 2, 65-74. [CrossRef]

14. Liu, C.; Gui, Q. Mapping intellectual structures and dynamics of transport geography research: A scientometric overview from 1982 to 2014. Scientometrics 2016, 109, 159-184. [CrossRef]

15. Peng, Y.; Lin, A.; Wang, K.; Liu, F.; Zeng, F.; Yang, L. Global trends in dem-related research from 1994 to 2013 : A bibliometric analysis. Scientometrics 2015, 105, 347-366. [CrossRef]

16. Li, L.; Liu, Y.; Zhu, H.; Ying, S.; Luo, Q.; Luo, H.; Kuai, X.; Xia, H.; Shen, H. A bibliometric and visual analysis of global geo-ontology research. Comput. Geosci. 2016, 99, 1-8. [CrossRef]

17. Huang, Q.; Yang, X.; Gao, B.; Yang, Y.; Zhao, Y. Application of DMSP/OLS nighttime light images: A meta-analysis and a systematic literature review. Remote Sens. 2014, 6, 6844-6866. [CrossRef]

18. Garfield, E. From the science of science to scientometrics visualizing the history of science with histcite software. J. Informetr. 2009, 3, 173-179. [CrossRef]

19. Lee, S.; Bozeman, B. The impact of research collaboration on scientific productivity. Soc. Stud. Sci. 2005, 35, 673-702. [CrossRef]

20. Savic, M.; Ivanovic, M.; Radovanovic, M.; Ognjanovic, Z.; Pejovic, A.; Kruger, T.J. The structure and evolution of scientific collaboration in serbian mathematical journals. Scientometrics 2014, 101, 1805-1830. [CrossRef]

21. Kernighan, B.W.; Lin, S. An efficient heuristic procedure for partitioning graphs. Bell Syst. Tech. J. 1970, 49, 291-307. [CrossRef]

22. Wasserman, S.; Faust, K. Social Network Analysis: Methods and Applications; Cambridge University Press: Cambridge, UK, 1994; Volume 8.

23. Newman, M.E.; Girvan, M. Finding and evaluating community structure in networks. Phys. Rev. E 2004, 69, 026113. [CrossRef] [PubMed]

24. Chinchillarodriguez, Z.; Ferligoj, A.; Miguel, S.; Kronegger, L.; De Moyaanegon, F. Blockmodeling of co-authorship networks in library and information science in argentina: A case study. Scientometrics 2012, 93, 699-717. [CrossRef] 
25. Bastian, M.; Heymann, S.; Jacomy, M. Gephi: An open source software for exploring and manipulating networks. In Proceedings of the 3rd International AAAI Conference on Weblogs and Social Media (ICWSM), San Jose, CA, USA, 17-20 May 2009; Volume 8, pp. 361-362.

26. Yan, D.; Zhao, Z.; Ng, W.; Liu, S. Probabilistic convex hull queries over uncertain data. IEEE Trans. Knowl. Data Eng. 2015, 27, 852-865. [CrossRef]

27. Xie, P. Study of international anticancer research trends via co-word and document co-citation visualization analysis. Scientometrics 2015, 105, 611-622. [CrossRef]

28. Chen, C.; Morris, S. Visualizing evolving networks: Minimum spanning trees versus pathfinder networks. In Proceedings of the 2003 IEEE Symposium on Information Visualization (INFOVIS 2003), Seattle, WA, USA, 19-21 October 2003.

29. Chen, C. Citespace II: Detecting and visualizing emerging trends and transient patterns in scientific literature. J. Am. Soc. Inf. Sci. Technol. 2006, 57, 359-377. [CrossRef]

30. Boyack, K. Using detailed maps of science to identify potential collaborations. Scientometrics 2008, 79, $27-44$. [CrossRef]

31. Börner, K.; Klavans, R.; Patek, M.; Zoss, A.M.; Biberstine, J.R.; Light, R.P.; Larivière, V.; Boyack, K.W. Design and update of a classification system: The UCSD map of science. PLoS ONE 2012, 7, e39464. [CrossRef] [PubMed]

32. Chen, C.; Leydesdorff, L. Patterns of connections and movements in dual-map overlays: A new method of publication portfolio analysis. J. Assoc. Inf. Sci. Technol. 2014, 65, 334-351. [CrossRef]

33. Li, D.; Li, X. An overview on data mining of nighttime light remote sensing. Acta Geod. Cartogr. Sin. 2015, 44, 591-601.

34. Newman, M.E.J. Communities, modules and large-scale structure in networks. Nat. Phys. 2012, 8, $25-31$. [CrossRef]

35. Watts, D.J.; Strogatz, S.H. Collective dynamics of 'small-world'networks. Nature 1998, 393, 440-442. [CrossRef] [PubMed]

36. Miller, S.D.; Haddock, S.; Elvidge, C.; Lee, T. Twenty thousand leagues over the seas: The first satellite perspective on bioluminescent 'milky seas'. Int. J. Remote Sens. 2006, 27, 5131-5143. [CrossRef]

37. Miller, S.D.; Mills, S.P.; Elvidge, C.D.; Lindsey, D.T.; Lee, T.F.; Hawkins, J.D. Suomi satellite brings to light a unique frontier of nighttime environmental sensing capabilities. Proc. Natl. Acad. Sci. USA 2012, 109, 15706-15711. [CrossRef] [PubMed]

38. Miller, S.D.; Straka, W.C.; Mills, S.; Elvidge, C.D.; Lee, T.F.; Solbrig, J.E.; Walther, A.; Heidinger, A.K.; Weiss, S. Illuminating the capabilities of the suomi national polar-orbiting partnership (NPP) visible infrared imaging radiometer suite (VIIRS) day/night band. Remote Sens. 2013, 5, 6717-6766. [CrossRef]

39. Cho, K.; Ito, R.; Shimoda, H.; Sakata, T. Technical note and cover fishing fleet lights and sea surface temperature distribution observed by DMSP/OLS sensor. Int. J. Remote Sens. 1999, 20, 3-9. [CrossRef]

40. Straka, W.; Seaman, C.; Baugh, K.; Cole, K.; Stevens, E.; Miller, S.D. Utilization of the suomi national polar-orbiting partnership (NPP) visible infrared imaging radiometer suite (VIIRS) day/night band for arctic ship tracking and fisheries management. Remote Sens. 2015, 7, 971-989. [CrossRef]

41. Nghiem, S.; Balk, D.; Rodriguez, E.; Neumann, G.; Sorichetta, A.; Small, C.; Elvidge, C. Observations of urban and suburban environments with global satellite scatterometer data. ISPRS J. Photogramm. Remote Sens. 2009, 64, 367-380. [CrossRef]

42. Chand, T.R.K.; Badarinath, K.V.S.; Murthy, M.S.R.; Rajshekhar, G.; Elvidge, C.D.; Tuttle, B.T. Active forest fire monitoring in uttaranchal state, india using multi-temporal DMSP-OLS and modis data. Int. J. Remote Sens. 2007, 28, 2123-2132. [CrossRef]

43. Chand, T.R.K.; Badarinath, K.V.S.; Elvidge, C.D.; Tuttle, B.T. Spatial characterization of electrical power consumption patterns over india using temporal DMSP-OLS night-time satellite data. Int. J. Remote Sens. 2009, 30, 647-661. [CrossRef]

44. Lee, S.; Chiang, K.; Xiong, X.; Sun, C.; Anderson, S. The S-NPP VIIRS day-night band on-orbit calibration/characterization and current state of SDR products. Remote Sens. 2014, 6, 12427-12446. [CrossRef]

45. Lee, S.; Mcintire, J.; Oudrari, H.; Schwarting, T.; Xiong, X. A new method for SUOMI-NPP VIIRS day-night band on-orbit radiometric calibration. IEEE Trans. Geosci. Remote Sens. 2014, 53, 324-334.

46. Lee, S.; Cao, C. Soumi NPP VIIRS day/night band stray light characterization and correction using calibration view data. Remote Sens. 2016, 8, 138. [CrossRef] 
47. Cao, C.; Shao, X.; Uprety, S. Detecting light outages after severe storms using the S-NPP/VIIRS day/night band radiances. IEEE Geosci. Remote Sens. Lett. 2013, 10, 1582-1586. [CrossRef]

48. Moyer, D.; Mcintire, J.; Oudrari, H.; Mccarthy, J.K.; Xiong, X.; De Luccia, F.J. JPSS-1 VIIRS pre-launch response versus scan angle testing and performance. Remote Sens. 2016, 8, 141. [CrossRef]

49. Jing, X.; Shao, X.; Cao, C.; Fu, X.; Yan, L. Comparison between the suomi-NPP day-night band and DMSP-OLS for correlating socio-economic variables at the provincial level in China. Remote Sens. 2016, 8, 17. [CrossRef]

50. Zhao, M.; Cheng, W.; Zhou, C.; Li, M.; Wang, N.; Liu, Q. Spatial differentiation and morphologic characteristics of China's urban core zones based on geomorphologic partition. J. Appl. Remote Sens. 2017, 11, 016041. [CrossRef]

51. Ma, T.; Zhou, Y.; Zhou, C.; Haynie, S.; Pei, T.; Xu, T. Night-time light derived estimation of spatio-temporal characteristics of urbanization dynamics using DMSP/OLS satellite data. Remote Sens. Environ. 2015, 158, 453-464. [CrossRef]

52. Xu, T.; Ma, T.; Zhou, C.; Zhou, Y. Characterizing spatio-temporal dynamics of urbanization in China using time series of DMSP/OLS night light data. Remote Sens. 2014, 6, 7708-7731. [CrossRef]

53. Fan, J.; Ma, T.; Zhou, C.; Zhou, Y.; Xu, T. Comparative estimation of urban development in China's cities using socioeconomic and DMSP/OLS night light data. Remote Sens. 2014, 6, 7840-7856. [CrossRef]

54. Levin, N.; Zhang, Q. A global analysis of factors controlling VIIRS nighttime light levels from densely populated areas. Remote Sens. Environ. 2017, 190, 366-382. [CrossRef]

55. Zhang, Q.; Li, B.; Thau, D.; Moore, R. Building a better urban picture: Combining day and night remote sensing imagery. Remote Sens. 2015, 7, 11887-11913. [CrossRef]

56. Kyba, C.C.M.; Garz, S.; Kuechly, H.U.; De Miguel, A.S.; Zamorano, J.; Fischer, J.; Holker, F. High-resolution imagery of earth at night: New sources, opportunities and challenges. Remote Sens. 2014, 7, 1-23. [CrossRef]

57. Blake, S.; Dunlop, C.N.; Nandi, D.; Sharples, R.M.; Talbot, G.; Shanks, T.; Donoghue, D.N.M.; Galiatsatos, N.; Luke, P. New microslice technology for hyperspectral imaging. Remote Sens. 2013, 5, 1204-1219.

58. Zhuo, L.; Ichinose, T.; Zheng, J.; Chen, J.; Shi, P.; Li, X. Modelling the population density of China at the pixel level based on DMSP/OLS non-radiance-calibrated night-time light images. Int. J. Remote Sens. 2009, 30, 1003-1018. [CrossRef]

59. Zhuo, L.; Zheng, J.; Zhang, X.; Li, J.; Liu, L. An improved method of night-time light saturation reduction based on EVI. Int. J. Remote Sens. 2015, 36, 4114-4130. [CrossRef]

60. Zhang, Q.; Schaaf, C.; Seto, K.C. The vegetation adjusted ntl urban index: A new approach to reduce saturation and increase variation in nighttime luminosity. Remote Sens. Environ. 2013, 129, 32-41. [CrossRef]

61. Li, X.; Chen, X.; Zhao, Y.; Xu, J.; Chen, F.; Li, H. Automatic intercalibration of night-time light imagery using robust regression. Remote Sens. Lett. 2012, 4, 45-54. [CrossRef]

62. Li, X.Q.; Zhang, R.; Huang, C.; Li, D. Detecting 2014 northern Iraq insurgency using night-time light imagery. Int. J. Remote Sens. 2015, 36, 3446-3458. [CrossRef]

63. Li, X.; Li, D. Can night-time light images play a role in evaluating the Syrian crisis? Int. J. Remote Sens. 2014, 35, 6648-6661. [CrossRef]

64. Elvidge, C.D.; Baugh, K.E.; Anderson, S.J.; Sutton, P.C.; Ghosh, T. The night light development index (NLDI): A spatially explicit measure of human development from satellite data. Soc. Geogr. 2012, 7, 23-35. [CrossRef]

65. Elvidge, C.D.; Ziskin, D.; Baugh, K.E.; Tuttle, B.T.; Ghosh, T.; Pack, D.W.; Erwin, E.H.; Zhizhin, M. A fifteen year record of global natural gas flaring derived from satellite data. Energies 2009, 2, 595-622. [CrossRef]

66. Elvidge, C.D.; Sutton, P.C.; Ghosh, T.; Tuttle, B.T.; Baugh, K.E.; Bhaduri, B.; Bright, E. A global poverty map derived from satellite data. Comput. Geosci. 2009, 35, 1652-1660. [CrossRef]

67. Doll, C.N.; Muller, J.-P.; Morley, J.G. Mapping regional economic activity from night-time light satellite imagery. Ecol. Econ. 2006, 57, 75-92. [CrossRef]

68. Elvidge, C.; Tuttle, B.; Sutton, P.; Baugh, K.; Howard, A.; Milesi, C.; Bhaduri, B.; Nemani, R. Global distribution and density of constructed impervious surfaces. Sensors 2007, 7, 1962-1979. [CrossRef]

69. Elvidge, C.D.; Baugh, K.E.; Zhizhin, M.; Hsu, F.-C. Why VIIRS data are superior to DMSP for mapping nighttime lights. Proc. Asia-Pac. Adv. Netw. 2013, 35, 62-69. [CrossRef]

70. Elvidge, C.D.; Zhizhin, M.; Hsu, F.-C.; Baugh, K.E. VIIRS nightfire: Satellite pyrometry at night. Remote Sens. 2013, 5, 4423-4449. [CrossRef]

71. Baugh, K.; Hsu, F.-C.; Elvidge, C.D.; Zhizhin, M. Nighttime lights compositing using the VIIRS day-night band: Preliminary results. Proc. Asia-Pac. Adv. Netw. 2013, 35, 70-86. [CrossRef] 
72. Li, X.; Xu, H.; Chen, X.; Li, C. Potential of NPP-VIIRS nighttime light imagery for modeling the regional economy of China. Remote Sens. 2013, 5, 3057-3081. [CrossRef]

73. Zhang, Q.; Seto, K.C. Mapping urbanization dynamics at regional and global scales using multi-temporal DMSP/OLS nighttime light data. Remote Sens. Environ. 2011, 115, 2320-2329. [CrossRef]

74. Zhou, Y.; Smith, S.J.; Elvidge, C.D.; Zhao, K.; Thomson, A.M.; Imhoff, M.L. A cluster-based method to map urban area from DMSP/OLS nightlights. Remote Sens. Environ. 2014, 147, 173-185. [CrossRef]

75. Blondel, V.D.; Guillaume, J.-L.; Lambiotte, R.; Lefebvre, E. Fast unfolding of communities in large networks. J. Stat. Mech. Theory Exp. 2008, 2008. [CrossRef]

76. Jendryke, M.; Balz, T.; McClure, S.C.; Liao, M. Putting people in the picture: Combining big location-based social media data and remote sensing imagery for enhanced contextual urban information in Shanghai. Comput. Environ. Urban Syst. 2017, 62, 99-112. [CrossRef]

C 2017 by the authors. Licensee MDPI, Basel, Switzerland. This article is an open access article distributed under the terms and conditions of the Creative Commons Attribution (CC BY) license (http://creativecommons.org/licenses/by/4.0/). 